\title{
A Hybrid Fuzzy Multi-criteria Decision Making Model for Selecting a Sustainable Supplier of Forklift Filters: A Case Study from the Mining Industry
}

\author{
Miguel Ortiz-Barrios \\ Department of Industrial Management, Agroindustry and Operations, Universidad de la Costa CUC, \\ Barranquilla, Colombia \\ $\underline{\text { mortiz1@ cuc.edu.co }}$ \\ Juan Cabarcas-Reyes \\ Department of Industrial Engineering, Universidad del Atlántico, Barranquilla, Colombia \\ juancabarcas@uniatlantico.edu.co \\ Alessio Ishizaka \\ NEOMA Business School, 1 rue du Maréchal Juin - 76130 Mont-Saint-Aignan, France \\ Alessio.ISHIZAKA@neoma-bs.fr \\ Maria Barbati \\ University of Portsmouth, Portsmouth Business School, Richmond Building, Portland Street, \\ Portsmouth PO1 3DE, United Kingdom \\ maria.barbati@port.ac.uk \\ Natalia Jaramillo-Rueda \\ Department of Industrial Management, Agroindustry and Operations, Universidad de la Costa CUC, \\ Barranquilla, Colombia \\ njaramil@cuc.edu.co \\ Giovani de Jesús Carrascal-Zambrano \\ Department of Industrial Engineering, Universidad del Atlántico, Barranquilla, Colombia \\ gcarrascal@mail.uniatlantico.edu.co
}

\begin{abstract}
Supplier selection has long been a strategic cornerstone for the advancement of companies from the mining sector due to its impact on many sectors as inventory management, production planning, maintenance scheduling, financial resources and environment. In this regard, expert decision-makers should deem a number of performance conflicting criteria and supplier alternatives. Moreover, choosing a suitable Multi-Criteria Decision Making (MCDM) approach has become a key strategic consideration for supplier selection. Hence, this paper presents a combination of powerful MCDM methods to select the most suitable supplier of forklift filters. The Fuzzy Analytic Hierarchy Process (FAHP) is first used to calculate the initial weights of criteria and sub-criteria under uncertainty, followed by the implementation of Fuzzy Decision Making Trial and Evaluation Laboratory (FDEMATEL) to assess the interrelations and feedback between them. The fuzzy theory is used in both AHP and DEMATEL methods to represent the human vagueness when making judgments. Then, FAHP and FDEMATEL are combined to obtain the final contributions of both criteria and sub-criteria on the basis of interrelations
\end{abstract}


and uncertainty. Finally, the Technique for Order of Preference by Similarity to Ideal Solution (TOPSIS) is used to rank the supplier alternatives. To validate the effectiveness of the proposed framework, a case study is presented. The results evidence that quality criterion is the most crucial aspect when selecting suppliers of forklift filters.

Keywords: Multicriteria Decision-Making (MCDM), Fuzzy AHP (FAHP), Fuzzy DEMATEL (FDEMATEL), TOPSIS, Mining Industry, Supplier Selection, Sustainability

\section{Introduction}

Nowadays organizations recognize the importance of sustainability and it has become an integral part of their business strategy. The main idea of sustainability is to maintaining a harmonious balance respecting the environmental and social concerns, while pursuing economic objectives (Faisal et al. 2017). In the case of non-renewable resources, like minerals, the task is highly challenging. In fact, it is necessary to meet the needs of the current generation but also to sustain and enhance its other resources or develop new ones, which future generations can rely on. Despite being a fundamental objective to achieve sustainability, Sauer,Seuring (2017) found in their review that research for a sustainable mining industry has been scarce. Whilst there is a pressure from the different stakeholders to develop sustainable strategies (Schneider,Wallenburg 2012), there is also a debate in the ability to adopt the core principles of sustainability by the mining companies (Sauer,Seuring 2017). In fact, the mining industry is known to have a poor environmental reputation (Muduli et al. 2013). This have forced many mining companies to face competitive, regulatory, and community/social pressures causing increased consideration of greening their supply chains (Kusi-Sarpong et al. 2016). One way to improve the supply chain is to select better suppliers (Igarashi et al. 2013). Suppliers impact all the value chain and also the sustainability performance of the company. Therefore, it is indicated to have a structured approach in the selection process (Chai et al. 2013). Moreover, as selecting a supplier is based on several criteria, which are often conflicting, a structured decision-making approach, as in multi-criteria decision making (MCDM) methods, can help managers in this exercise (Ishizaka,Nemery 2013a). MCDM can take into account several conflicting criteria, including sustainable criteria. In this paper, we present a hybrid MCDM model for selecting a sustainable supplier. The Fuzzy Analytic Hierarchy Process (FAHP) is first applied to calculate the initial weights of criteria and sub-criteria under uncertainty, followed by the implementation of Fuzzy Decision Making Trial and Evaluation Laboratory (FDEMATEL) to assess the interrelations and feedback between the decision elements. The fuzzy theory is used in both AHP and DEMATEL methods to represent the human vagueness when making judgments. Then, FAHP and FDEMATEL are combined to obtain the final contributions of both criteria and sub-criteria on the basis of interrelations and uncertainty. Finally, the Technique for Order of Preference by Similarity to Ideal Solution (TOPSIS) is used to rank the supplier alternatives. A case study is presented to validate the effectiveness of the proposed framework.

The rest of the paper is structured as follows. Section 2 reviews the literature on supplier selection. Section 3 presents the new hybrid method. Section 4 describes the case study.

Finally, section 5 concludes the paper. 


\section{Literature review}

The supplier selection problem represents a very complex problem due to the presence of many decision levels and different aspects to be considered (Sultana et al. 2015). At the same time, the importance in the whole supply chain management and the effects on the performance of the selection should be as much as possible careful and justified (Khan et al. 2018). For these reasons, in the literature several approaches have been proposed to deal with such problems (for a review see e.g., (Chai et al. 2013)). One of the most common used approaches is the MCDM method that supports the managers to select the suppliers, based on the defined criteria and their appropriate evaluations (Kahraman et al. 2003). Among the several MCDM approaches (Ho et al. 2010), the Fuzzy MCDM approaches (FMCDM) are gaining a much increasing importance, thanks to the possibility of tackling conflicting interests in very complex problems (Mardani et al. 2015).

One of the most used method is the Fuzzy Analytic Hierarchy Process (FAHP) (Luthra et al. 2017) that in addition to the advantages of the AHP, integrates the possibility of considering the fuzziness of the data for deciding the preferences of the different criteria listed (Ishizaka 2014). For example, Kahraman et al. (2003), applied FAHP to the selection of the best supplier companies for a white good manufacturer in Turkey, while Chan,Kumar (2007) developed it for a global supplier selection problem of a manufacturing organization. The fuzzy Analytic Network Process (FANP) has also been used several times in literature for supplier selection (Chai et al. 2013). An example is provided in (Vinodh et al. 2011) where a conceptual model for supplier selection has been developed for an Indian manufacturing company of electronics switches.

In addition, the AHP, and even the ANP, integration with other approach is very much popular given its flexibility, its simplicity to be understood and its capability of adaptation to different contexts with several criteria defined (Govindan et al. 2015; Zavadskas et al. 2016; Barrios et al. 2016). Mainly, in these approaches, FAHP has adopted to assess weights of the listed criteria while a second approach that uses those weights is adopted to ranking the suppliers. For example, Sivrikaya et al. (2015) integrated FAHP with a goal programming approach. Furthermore, Kar (2015) employed FAHP to evaluate the group preferences for an Indian manufacturing company integrating it with the fuzzy Neural Network that maps the supplier using the weights generated by the FAHP approach.

In many cases, FAHP was adopted together with TOPSIS or Fuzzy TOPSIS. In this sense, Kannan et al. (2013) used the combined approach to select the best green suppliers for an Iranian automobile manufacturing company, also used in a similar context by (Shen et al. 2013). Sultana et al. (2015) integrated in addition to FAHP and Fuzzy TOPSIS also Fuzzy Delphi method to identify the most important criterion for a leading multinational manufacturing company of battery for several vehicles in Bangladesh. Similarly, Prakash,Barua (2016) adopted the combinations of these methods for the selection of the reverse logistics partners of an Indian electronics industry.

These MCDM methodologies can be also supported by the DEMATEL and its fuzzy variant FDEMATEL methods that are well established in the field of the supplier selection (see e.g., (Chang et al. 2011)). Baykasoğlu et al. (2013) integrated FDEMATEL to evaluate the weights of the criteria with TOPSIS method to choose among the alternative supplier of trucks for a land transportation company. In a different context, in particular for a communication company in Turkey, Uygun et al. (2015) studied the interrelationship among the main criteria through the DEMATEL method while local weights of the 
sub-criteria were generated by a FANP approach on the basis of cause-effect relationships derived with the DEMATEL method. FDEMATEL has been combined also with other methodologies as in (Mehregan et al. 2014) where for the selection of the supplier of the national Iranian gas company it was combined with interpretive structural modelling, or in (Keskin 2015) where is joint with Fuzzy c-means algorithm for a glass makers company. Recently, Lin et al. (2018) proposed an approximate FDEMATEL and applied it to a can factory in Jordan.

Lately, the combination with more than one MCDM method together with the FDEMATEL has been proposed. Büyüközkan,Çifçi (2012) applied a hybrid MCDM approach to evaluate green suppliers for an automotive manufacturing company in Turkey. The combined fuzzy ANP and fuzzy DEMATEL method helped to better understand the interdependent relationships within and among the set of criteria while fuzzy TOPSIS method facilitated the choice of the alternatives for the ideal green supplier.

This topic, i.e., the selection of green suppliers and more in general the implementation of the sustainable supply chain is vastly increasing in the last years (Zimmer et al. 2016). As highlighted by Tseng et al. (2019) there is a rising tendency of applying MCDM models for supporting informed decisions that address environmental performance. The selection of the suppliers becomes a fundamental step for the creation of the sustainable supply chain (Maditati et al. 2018) and a definition of appropriate criteria is essential to create such a type of supply chain (Guarnieri,Trojan 2019). For this reason, we have stressed out in our paper how the selection of supplier in the mining industry should be as sustainable as possible and, therefore, it is essential to take into account sustainability aspects when evaluating suppliers. Indeed, despite the increasing interest in involving sustainable criteria, the development of structured and participative MCDM methods that can tackle supplier selection problems while taking into account sustainable criteria is still scarce.

In this direction, an attempt can be retrieved in Orji,Wei (2014) that applied Fuzzy logic, DEMATEL and TOPSIS to highlight the interdependencies between sustainability criteria in order to select the best sustainable supplier in fuzzy environment for a gear manufacturing company in China. Similarly, Petrudi et al. (2018) investigated interrelationships among sustainability criteria, weighted them, and then evaluated suppliers according to these criteria adopting FDEMATEL, Fuzzy Preference Programming, ANP and finally Fuzzy TOPSIS.

To be precise, the novelty of our approach consists in using a combination of MCDM methods (FAHP and TOPSIS together with FDEMATEL) that integrates the advantages of fuzzy DEMATEL in establishing interrelationships between several criteria, with the strength in using the fuzzy AHP method to prioritize the criteria and finally TOPSIS to rank the different alternatives for ranking supplier selection according to a variety of criteria including the sustainable ones. The only other paper, at the best of our knowledge, that proposed a similar combination of techniques for the supplier selection problems was proposed by Abdulgader et al. (2018). However, they have explained their methodology through a demo application. Instead, our paper tackles a real case from a major company and takes into account sustainability aspects of the problem according to the last trend in the literature. We also interact in a structured and participative way with several stakeholders of the company. Indeed, our approach is original because it considers a novel combination of MCDM methods that has never been applied in the mining industry for the sustainable selection of the suppliers. We aim to show how it can help the 
decisions makers in such complex decisions and improve the sustainability of the mining industry still optimizing other conflicting objectives at the same time.

\section{Methods}

\subsection{Description of the proposed methodology}

Multicriteria techniques can solve four different types of problems (Roy 1981):

a) Choice problem: The goal is to select a single best action or to reduce the group of actions to a subset of equivalent or incomparable actions.

b) Sorting problem or similarity analysis problems: Actions are sorted into ordered predefined categories.

c) Ranking problem: Actions are ordered in a decreasing preference. The order can be complete or partial if we consider incomparable actions.

d) Description problem: The goal is to help the description of actions and their consequences.

The proposed new methodology solves ranking problems and choice problem if we select only the first ranked alternative. A six-phase methodology (Fig. 1) is proposed to establish the most suitable supplier of forklift filters in the heavy machine sector:

Phase 1: a decision-making group is selected based on their experience for solving the problem. Then, the participants will be involved in the decision-making process through FAHP and FDEMATEL methods.

Phase 2: the decision elements (criteria and sub-criteria) are defined based on the experts' opinion and the pertinent scientific literature.

Phase 3: FAHP is applied to calculate the relative importance of criteria and sub-criteria under uncertainty. In this step, the participants are asked to provide pairwise comparisons that are then processed according to the FAHP method as described in Section 3.2.

Phase 4: FDEMATEL is implemented to determine the dispatchers and receivers as well as the strength of influence between criteria/sub-criteria. Herein, the experts evaluate the influence of each decision element on the others applying the step-by-step procedure explained in Section 3.3.

Phase 5: FAHP and FDEMATEL are combined to obtain the final criteria weights (Section 3.4).

Phase 6: TOPSIS method is applied to rank the suppliers based on their closeness coefficient (Section 3.5) and quickly identify the best option for a company using forklift filters. 


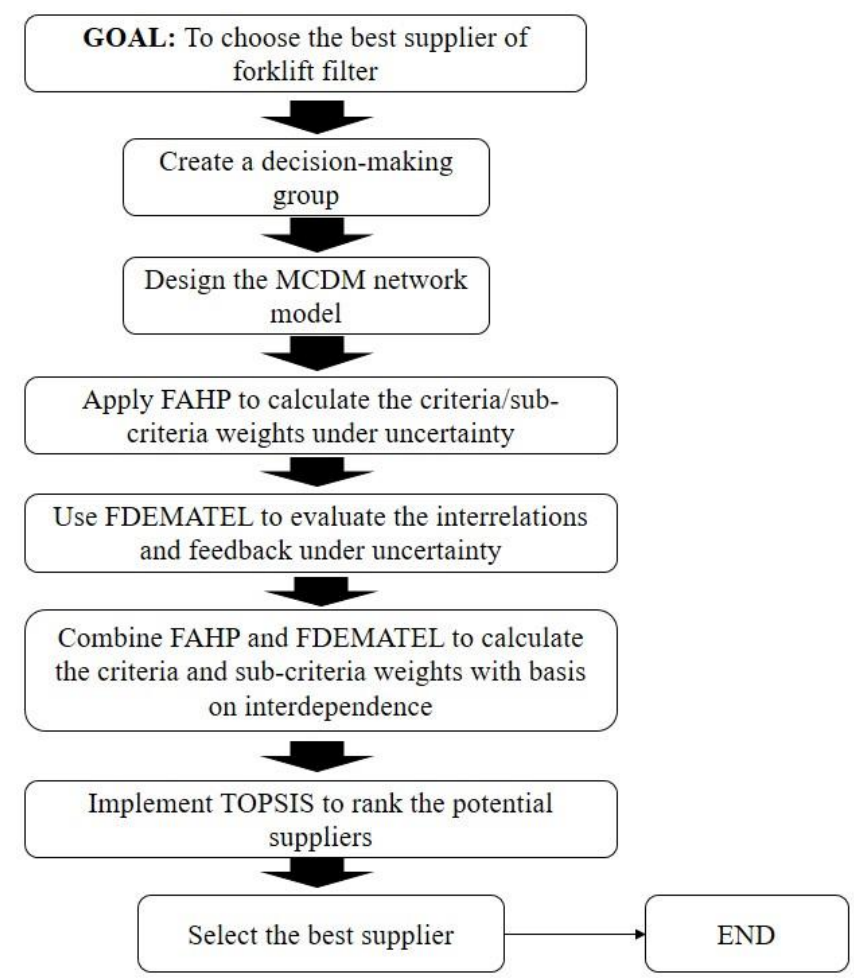

Figure 1. The proposed approach for selecting the most suitable suppliers of forklift filters in the heavy machine sector

\subsection{Fuzzy Analytic Hierarchy Process (FAHP)}

Fuzzy sets were introduced in the development of AHP methodology in order to cope with vagueness derived from human judgments, e.g. in the pairwise comparisons (Cebeci 2009). In this regard, Fuzzy sets provide more accuracy to solve real-world MCDM problems, which inexorably entails some degree of noise in their variables. With this modification, AHP becomes FAHP. The comparisons are described by triangular numbers $\mathrm{M}$ which are represented by $(a, b, c)$ and the membership function is defined as follows:

$$
\mu_{M}(x)=\left\{\begin{array}{ll}
\frac{x-a}{b-a}, & a \leq x \leq b \\
\frac{c-x}{c-b}, & b \leq x \leq c \\
0, & \text { otherwise }
\end{array} \quad \text { Here, }-\infty<a \leq b \leq c<\infty .\right.
$$

$a$ and $c$ are the lower and upper bounds whilst, the strongest grade is represented by parameter $\mathrm{b}$. The fuzzy triangular numbers to be used in FAHP and its corresponding reduced version of Saaty natural scale (Saaty 1977) are shown in Table 1. From the Saaty scale, only three points are adopted to facilitate the engagement of unskilled respondents and then reduce inconsistencies in the decision-making process. 
Table 1. Fuzzy triangular numbers used in FAHP

\begin{tabular}{|c|l|c|}
\hline Reduced AHP scale & Definition & Fuzzy triangular number \\
\hline $\mathbf{1}$ & Equally relevant & {$[1,1,1]$} \\
\hline $\mathbf{3}$ & More relevant & {$[2,3,4]$} \\
\hline $\mathbf{5}$ & Much more relevant & {$[4,5,6]$} \\
\hline $\mathbf{1 / 3}$ & Less relevant & {$[1 / 4,1 / 3,1 / 2]$} \\
\hline $\mathbf{1 / 5}$ & Much less relevant & {$[1 / 6,1 / 5,1 / 4]$} \\
\hline
\end{tabular}

The description of the FAHP algorithm is presented by phases:

- Phase 1: perform paired judgments for both criteria and subcriteria by using fuzzy triangular numbers described in Table 1. From this, a fuzzy judgment matrix $\tilde{A}^{k}\left(a_{i j}\right)$ can be obtained via applying Eq. 1:

$$
\tilde{A}^{K}=\left[\begin{array}{cccc}
\tilde{a}_{11}^{k} & \tilde{a}_{12}^{k} & \cdots & \tilde{a}_{1 n}^{k} \\
\tilde{a}_{21}^{k} & \tilde{a}_{22}^{k} & \cdots & \tilde{a}_{2 n}^{k} \\
\cdots & \cdots & \cdots & \cdots \\
\tilde{a}_{n 1}^{k} & \tilde{a}_{n 2}^{k} & \cdots & \tilde{a}_{n n}^{k}
\end{array}\right]
$$

$\tilde{a}_{i j}^{k}$ denotes the $k t h$ expert's preference of ith criterion/sub-criterion over $j t h$ criterion/subcriterion.

- Phase 2: If there is a committee of experts, the judgments are then aggregated by using Eq. 2, where $K$ is the number of experts participating in the decision-making process. Then, the initial fuzzy judgment matrix is updated as outlined in Eq. 3.

$$
\begin{gathered}
\tilde{a}_{i j}=\sqrt[K]{\tilde{a}_{i j}^{1} * \tilde{a}_{i j}^{2} * \cdots * \tilde{a}_{i j}^{k}} \\
\tilde{A}=\left[\begin{array}{ccc}
\widetilde{a_{11}} & \cdots & \widetilde{a_{1 n}} \\
\vdots & \ddots & \vdots \\
\tilde{a}_{n 1} & \cdots & \tilde{a}_{n n}
\end{array}\right]
\end{gathered}
$$

- Phase 3: Calculate the geometric mean of fuzzy comparisons $\left(\tilde{r}_{i}\right)$ for each criterion and subcriterion based on Eq. 4.

$$
\tilde{r}_{i}=\left(\prod_{j=1}^{n} \tilde{a}_{i j}\right)^{1 / n}, i=1,2, \ldots, n
$$

- Phase 4: Obtain the fuzzy weights of each criterion and sub-criterion $\left(\widetilde{w}_{i}\right)$ using Eq. 5.

$$
\widetilde{w}_{i}=\tilde{r}_{i} \otimes\left(\tilde{r}_{1} \oplus \tilde{r}_{2} \oplus \ldots \oplus \tilde{r}_{n}\right)^{-1}=\left(l w_{i}, m w_{i}, u w_{i}\right)
$$


- Phase 5: Defuzzify $\left(\widetilde{w}_{i}\right)$ by applying the Centre of Area method (Wang et al. 2009) outlined in Eq. 6 where $M_{i}$ is a non-fuzzy number.

$$
M_{i}=\frac{l w_{i}+m w_{i}+u w_{i}}{3}
$$

— Phase 6: Normalize $M_{i}$ using Eq. 7.

$$
N_{i}=\frac{M_{i}}{\sum_{i=1}^{n} M_{i}}
$$

\subsection{Fuzzy Decision Making Trial and Evaluation Laboratory}

Considering crisp values (experts' responses) do not properly represent the real-world context, FDEMATEL has been proposed as a suitable method to assess the interdependence between uncertain criteria/sub-criteria and subsequently identify causal relationships in complex MCDM networks. Fuzzy logic effectively represents the vagueness of human judgments and address the variability of real-world scenarios (Baykasoğlu et al. 2013). This approach also provides digraphs to classify the MCDM elements into two groups (cause and effect) so that focused improvement strategies can be proposed for increasing the suppliers' performance. The steps of FDEMATEL are described as follows:

Table 2. Fuzzy triangular numbers used in FDEMATEL

\begin{tabular}{|c|l|c|}
\hline DEMATEL scale & Definition & Fuzzy triangular number \\
\hline $\mathbf{0}$ & No influence & {$[0,0,0.25]$} \\
\hline $\mathbf{1}$ & Weak influence & {$[0,0.25,0.5]$} \\
\hline $\mathbf{2}$ & Medium influence & {$[0.25,0.5,0.75]$} \\
\hline $\mathbf{3}$ & Strong influence & {$[0.5,0.75,1]$} \\
\hline $\mathbf{4}$ & Very strong influence & {$[0.75,1,1]$} \\
\hline
\end{tabular}

- Phase 1 - Use a fuzzy linguistic scale: To incorporate the uncertainty of human comparisons, five linguistic levels are utilized to represent the "influence" between decision elements: No influence, Weak influence, Medium influence, Strong influence, Very strong influence. The comparison is a fuzzy triangular number $\left(l_{i j}^{k}, m_{i j}^{k}, r_{i j}^{k}\right)$, which represents the $k t h$ expert's preference of $i t h$ criterion/sub-criterion over $j t h$, as outlined in Table 2.

In case of an expert group, the judgments are averaged using Eq. 8-10, where $K$ is the number of experts.

$$
l_{i j}=\frac{\sum_{k=1}^{K} l_{i j}^{k}}{K}
$$




$$
\begin{aligned}
& m_{i j}=\frac{\sum_{k=1}^{K} m_{i j}^{k}}{K} \\
& r_{i j}=\frac{\sum_{k=1}^{K} r_{i j}^{k}}{K}
\end{aligned}
$$

- Phase 2 - Create the initial fuzzy direct-influence matrix: After gathering the experts' judgments, an initial fuzzy direct-influence matrix $\widetilde{\boldsymbol{D}}$ can be derived using Eq. 11.

$$
\widetilde{\boldsymbol{D}}=\left[\tilde{d}_{i j}\right]_{n \times m^{\prime}}, \quad \text { where } \tilde{d}_{i j}=\left(d_{i j}^{l}, d_{i j}^{m}, d_{i j}^{r}\right)
$$

- Phase 3 - Normalize the initial fuzzy direct-influence matrix: $\widetilde{\boldsymbol{D}}$ matrix is then normalized to obtain $\widetilde{N}$ (refer to Eq. 12)

$$
\begin{gathered}
\widetilde{\boldsymbol{N}}=\widetilde{\boldsymbol{D}} / u, \text { where } u=\max _{i j}\left\{\max _{i} \sum_{j=1}^{n} d_{i j}, \max _{j} \sum_{i=1}^{n} d_{i j}\right\}, i, j \in\{1,2, \ldots, n\} \\
\widetilde{\boldsymbol{N}}=\left[\tilde{e}_{i j}\right]_{n \times n}, \tilde{e}_{i j}=\left(e_{i j}^{l}, e_{i j}^{m}, e_{i j}^{r}\right)
\end{gathered}
$$

- Phase 4 - Obtain the fuzzy total-influence matrix: After computing $\widetilde{\boldsymbol{N}}=\left(N^{l}, N^{m}, N^{r}\right)$, where $\boldsymbol{N}^{l}=\left[e_{i j}^{l}\right]_{n \times n^{\prime}}, \boldsymbol{N}^{m}=\left[e_{i j}^{m}\right]_{n \times n^{\prime}}$, and $\boldsymbol{N}^{r}=\left[e_{i j}^{r}\right]_{n \times n}$, the fuzzy total-influence matrix $\widetilde{\boldsymbol{T}}$ can be achieved applying Eq. 13. In this formula, $I$ represents the identity matrix.

$$
\begin{gathered}
\qquad \widetilde{\boldsymbol{T}}=\left[\tilde{t}_{i j}\right]_{n \times n^{\prime}} \text { where } \tilde{t}_{i j}=\left(t_{i j}^{l}, t_{i j}^{m}, t_{i j}^{r}\right) \\
\text { Where } \boldsymbol{T}^{l}=\left[t_{i j}^{l}\right]_{n \times n}=\boldsymbol{N}^{l}\left(\boldsymbol{I}-\boldsymbol{N}^{l}\right)^{-1}, \quad \boldsymbol{T}^{m}=\left[t_{i j}^{m}\right]_{n \times n}=\boldsymbol{N}^{m}\left(\boldsymbol{I}-\boldsymbol{N}^{m}\right)^{-1} \\
\text { and } \boldsymbol{T}^{r}=\left[t_{i j}^{r}\right]_{n \times n}=\boldsymbol{N}^{r}\left(\boldsymbol{I}-\boldsymbol{N}^{r}\right)^{-1}
\end{gathered}
$$

The triangular fuzzy numbers in matrix $\widetilde{\boldsymbol{T}}$ are expressed as $\boldsymbol{T}^{l}=\left[t_{i j}^{l}\right]_{n \times n^{\prime}}, \boldsymbol{T}^{m}=\left[t_{i j}^{m}\right]_{n \times n^{\prime}}$ $\boldsymbol{T}^{m}=\left[t_{i j}^{m}\right]_{n x n}$, when $e_{i j}^{l}<e_{i j}^{m}<e_{i j}^{r}$ for any $i, j \in\{1,2, \ldots, n\}$.

- Phase 5 - Calculate the threshold value $(\boldsymbol{\alpha})$ : This value can be estimated using Eq. 14 so that the cause-and-effect diagram can be generated.

$$
\alpha=\frac{\sum_{i=1}^{n} \sum_{j=1}^{n} t_{i j}}{n^{2}}
$$

The sum of rows and columns are outlined as separate vectors $\tilde{C}_{i}$ and $\tilde{R}_{j}$ correspondingly, where $i=j$. Prominence values, represented on the horizontal axis, is achieved by summing 
the above-mentioned vectors. This variable measures the influence of each criterion/subcriterion on the other decision elements. Likewise, relation values $\left(\tilde{C}_{i}-\tilde{R}_{j}\right)$, represented on the vertical axis, categorize the decision elements as dispatchers and receivers. If $\left(\tilde{C}_{i}-\tilde{R}_{j}\right)$ is positive, the element is then categorized as a dispatcher; otherwise, it is considered as a receiver.

The next step is then implementing the CFCS (Converting Fuzzy data into Crisp scores) method outlined in Eq. 15-23 for defuzzifying $\left(\tilde{C}_{i}+\tilde{R}_{j}\right)$ and $\left(\tilde{C}_{i}-\tilde{R}_{j}\right)$. After this, the cause-and-effect diagram is achieved given the dataset $\left(\left(\tilde{C}_{i}+\tilde{R}_{j}\right)^{\operatorname{def}},\left(\widetilde{C}_{i}-\tilde{R}_{j}\right)^{d e f}\right)$.

\section{(i) Normalization}

$$
\begin{gathered}
x l_{i j}^{k}=\left(l_{i j}^{k}-\min l_{i j}^{k}\right) / \Delta_{\min }^{\max } \\
x m_{i j}^{k}=\left(m_{i j}^{k}-\min l_{i j}^{k}\right) / \Delta_{\min }^{\max } \\
x r_{i j}^{k}=\left(r_{i j}^{k}-\min l_{i j}^{k}\right) / \Delta_{\min }^{\max } \\
\text { Where } \Delta_{\min }^{\max }=\max r_{i j}^{k}-\min l_{i j}^{k}
\end{gathered}
$$

(ii) Calculate left (ls) and right (rs) normalized values:

$$
\begin{aligned}
& x l s_{i j}^{k}=x m_{i j}^{k} /\left(1+x m_{i j}^{k}-x l_{i j}^{k}\right) \\
& x r s_{i j}^{k}=x r_{i j}^{k} /\left(1+x r_{i j}^{k}-x m_{i j}^{k}\right)
\end{aligned}
$$

(iii) Establish the total normalized crisp value:

$$
x_{i j}^{k}=\left[x l s_{i j}^{k}\left(1-x l s_{i j}^{k}\right)+x r s_{i j}^{k} x r s_{i j}^{k}\right] /\left[1-x l s_{i j}^{k}+x r s_{i j}^{k}\right]
$$

(iv) Calculate the crisp value:

$$
z_{i j}^{k}=\min l_{i j}^{k}+x_{i j}^{k} \Delta_{\min }^{\max }
$$

\section{(v) Integrate the crisp values:}




$$
z_{i j}=\frac{1}{K}\left(z_{i j}^{1}+z_{i j}^{2}+\cdots+z_{i j}^{K}\right)
$$

\subsection{The FAHP-FDEMATEL approach}

In this work, our primary objective is to generate a robust MCDM model for i) ranking sustainable supplier alternatives of forklift filters and ii) identifying the deficiencies that should be tackled by each supplier to effectively underpin sustainability. The weights consider both the short term and long term intervention which is consistent with the time horizons specified in the development plans of companies from the heavy machine building industry. A hybrid FAHP-FDEMATEL approach is then proposed to calculate these weights. This method also addresses the weaknesses of FAHP approach which, in a single way, does not evaluate the-fuzzy interrelations often found in models supporting sustainable supplier selection (Phochanikorn, Tan 2019; Chen et al. 2020).

The final global criterion $(k=1,2, \ldots, m)$ weight $G W_{k}$, local sub-criterion $(i=1,2, \ldots, s)$ weight $L W_{i}^{k}$, and global sub-criterion $(i=1,2, \ldots, s)$ contribution $G W_{i}$ resulting from FAHP-FDEMATEL can be obtained using Eq. 24, Eq. 25, and Eq. 26 correspondingly. Here, $m$ represents the total number of criteria while $s$ denotes the total number of sub-criteria considered in the performance assessment model. $\left(\check{C}_{k}+\check{R}_{k}\right)^{d e f}$ and $\left(\check{C}_{k}-\check{R}_{k}\right)^{d e f}$ correspond to the prominence and relation values of criterion $k(k=1$, $2, \ldots, m)$ while $\left(\check{C}_{i}+\check{R}_{i}\right)^{\text {def }}$ and $\left(\check{C}_{i}-\check{R}_{i}\right)^{\text {def }}$ describe the prominence and relation of sub-criterion $i(i=$ $1,2, \ldots, s)$. Eq. 24 and 25 combine the weights provided by F-DEMATEL and F-AHP to estimate the criteria and sub-criteria weights on the basis of interdependence. In particular, F-DEMATEL weights for criteria are calculated according to: $w_{j}=\sqrt[2]{\left(\check{C}_{j}^{\text {def }}+\check{R}_{j}^{\text {def }}\right)^{2}+\left(\check{C}_{j}^{\text {def }}-\breve{R}_{j}^{\text {def }}\right)^{2}}$ (Baykasoğlu et al. 2013; Keskin 2015; Si et al. 2018). This equation incorporates both prominence and relation measures in one single weight through the vector length method $\left(|\bar{a}|=\sqrt[2]{a_{x}^{2}+a_{y}^{2}}\right)$. In fact, although $\left(\check{C}_{j}^{\text {def }}+\check{R}_{j}^{\text {def }}\right)-$ prominence - (x-component: used for identifying the influence strength of criteria/sub-criteria) and $\left(\check{C}_{j}^{\text {def }}-\check{R}_{j}^{\text {def }}\right)$ - relation - (y-component: applied for discriminating between dispatchers and receivers) have different interpretations, their dimensionality is equal and can be therefore mathematically integrated as observed in $w_{j}$ formula. The F-DEMATEL weights are later integrated with FAHP weights represented by vector $N$ (Eq. 7). Finally, the denominator in Eqs. 24 and 25 is included for normalizing the criteria and sub-criteria weights. These are the resulting weights on the basis of interdependence that are used during the decision-making process.

$$
G W_{k}=\frac{\sqrt[2]{\left(N_{k}\left(\tilde{C}_{k}+\tilde{R}_{k}\right)^{d e f}\right)^{2}+\left(N_{k}\left(\tilde{C}_{k}-\tilde{R}_{k}\right)^{d e f}\right)^{2}}}{\sum_{k=1}^{m} \sqrt[2]{\left(N_{k}\left(\tilde{C}_{k}+\tilde{R}_{k}\right)^{d e f}\right)^{2}+\left(N_{k}\left(\tilde{C}_{k}-\tilde{R}_{k}\right)^{d e f}\right)^{2}}}
$$




$$
\begin{aligned}
& L W_{i}^{k}=\frac{\sqrt[2]{\left(N_{i}\left(\tilde{C}_{i}+\tilde{R}_{i}\right)^{d e f}\right)^{2}+\left(N_{i}\left(\tilde{C}_{i}-\tilde{R}_{i}\right)^{d e f}\right)^{2}}}{\sum_{i=1}^{s} \sqrt[2]{\left(N_{i}\left(\tilde{C}_{i}+\tilde{R}_{i}\right)^{d e f}\right)^{2}+\left(N_{i}\left(\tilde{C}_{i}-\tilde{R}_{i}\right)^{d e f}\right)^{2}}} \\
& G W_{i}=L W_{i}^{k} * G W_{k}
\end{aligned}
$$

\subsection{Technique for Order of Preference by Similarity to Ideal Solution}

TOPSIS is an MCDM ranking technique that chooses, from a finite set of options, the alternative with the shortest distance from the ideal solution and the farthest distance from the negative ideal solution (Ashtiani et al. 2009; Chai et al. 2013). The positive ideal solution is comprised of all the best criterion/sub-criterion values $\left(A^{+}\right)$; in contrast, the negative scenario represents the worst attribute values $\left(A^{-}\right)$. TOPSIS then calculate a closeness coefficient for each alternative so that the best alternative can be identified quickly (Olson 2004). This method originally works based on criteria/sub-criteria weights subjectively provided by decision makers; however, in this study, they are provided by the FAHP-FDEMATEL approach. The TOPSIS procedure can be expressed in a series of steps:

- Step 1: Establish an initial decision matrix $X$ with " $p$ " suppliers of forklift filters and " $n$ " subcriteria (Eq. 27). $x_{i j}$ denotes the value of the sub-criterion $S F_{j}(j=1,2,3, \ldots, n)$ in each supplier $S_{i}(i=1,2, \ldots, p)$. To do this, performance indicators need to be defined for each subcriterion and then gathered for each supplier.

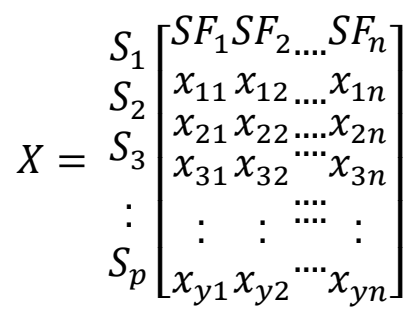

- Step 2: Standardize $X$ matrix by converting $x_{i j}$ into normalized measures $s_{i j}$ (Eq. 28). Let $n_{i j}$ be the norm used by TOPSIS (Eq. 29).

$$
\begin{gathered}
S=X \cdot n_{i j} \\
n_{i j}=\frac{x_{i j}}{\sqrt{\sum_{i=1}^{y} x_{i j}^{2}}}
\end{gathered}
$$

- Step 3: Calculate the weighted normalized decision matrix $V$ (Eq.30). The set of importance weights $\left(w_{j}\right)$ are provided by the FAHP-FDEMATEL approach.

$$
V=\left[w_{j} s_{i j}\right]=\left[v_{i j}\right]
$$


- Step 4: Identify the positive $\left(A^{+}\right)$and reverse $\left(A^{-}\right)$extreme performance of each criterion/subcriterion using Eq. 31-32 correspondingly:

$$
\begin{aligned}
& A^{+}=\left\{\left(\max _{i} s_{i j} \mid j \in J\right),\left(\min _{i} s_{i j} \mid j \in J\right) \text { for } i=1,2, \ldots, p\right\}=\left\{s_{1}^{+}, s, \ldots, s, \ldots, s\right\} \\
& A^{-}=\left\{\left(\min _{i} s_{i j} \mid j \in J\right),\left(\max _{i} s_{i j} \mid j \in J^{\prime}\right) \text { for } i=1,2, \ldots, p\right\}=\left\{s_{1}^{-}, s, \ldots, s_{j}^{-}, \ldots, s_{n}^{-}\right\}
\end{aligned}
$$

Where:

$$
\begin{gathered}
J=\{j=1,2, \ldots, n \mid j \text { associated } \text { with the benefit sub }- \text { criterion/criterion }\} \\
J^{\prime}=\{j=1,2, \ldots, n \mid j \text { associated with the cost sub }- \text { criterion/criterion }\}
\end{gathered}
$$

- Step 5: Set the distance measures of each supplier to both ideal $\left(A^{+}\right)$and nadir $\left(A^{-}\right)$using the Euclidean distance as outlined in Eq. 33-34.

Distance to $\left(A^{+}\right)$

$$
s_{i}^{+}=\sqrt{\sum_{j=1}^{n}\left(s_{i j}-s_{j}^{+}\right)^{2}} \quad i=1,2, \ldots, p
$$

Distance to $\left(A^{-}\right)$

$$
s_{i}^{-}=\sqrt{\sum_{j=1}^{n}\left(s_{i j}-s_{j}^{-}\right)^{2}} \quad i=1,2, \ldots, p
$$

- Step 6: For each supplier of forklift filters, determine the closeness coefficient $\left(R_{i}\right)$ applying Eq. 35. If $R_{k}=1$, the supplier performance is equal to $\left(A^{+}\right)$. Therefore, high $R_{i}$ values indicate satisfactory supplier's behaviour.

$$
R_{i}=\frac{s_{i}^{+}}{\left(s_{i}^{+}+s_{i}^{-}\right)}, \quad 0<R_{i}<1, \quad i=1,2, \ldots, p
$$

- Step 7: Rank the suppliers of forklift filters by maximizing $R_{i}$ values obtained in Step 6.

\section{Case study}

\subsection{Background}

Selecting a wrong supplier can have many negative effects (Barthélemy 2001; Stringfellow et al. 2008). A company can face unexpected maintenance costs due to poor performing suppliers. If the supply is 
unreliable, it has a repercussion of the inventory and the production planning. If the quality or the environmental compliance is not at the required standard, we may face a loss of customers. If the innovation capability of the supplier is low we may lose in competitiveness. All these negative effects have a high cost and may even lead to the bankruptcy of the company. These are particular concerns of a company from the heavy machine building industry, which outsources the production of forklift filters, components that are used in heavy-duty-forklift trucks for removing pollen, mud, solid particles, dust and other contaminants that may negatively affect the engine combustion system. Given the continuous operation of these machines in warehouses and stockyards for long hours under extreme weather conditions and environmental contaminants (dust and dirt), the filters have to be averagely changed every 300 hours. Hence, selecting a suitable supplier of forklift filters is a critical decision for mining companies. In reply, a practical and managerial MCDM approach was proposed to be implemented in this sector. This MCDM method evaluates several criteria to select the best supplier to minimize the risk of post selection problems. A pilot study was then conducted in a Colombian leading firm with more than 10 years of experience and export tradition in North America and Europe. This company is involved in a continuous improvement plan targeting their supply chain performance, which should satisfactorily respond to customer requirements at the lowest cost.

\subsection{Creation of the decision-making group}

The suppliers play a relevant role and should be therefore rigorously selected. This intervention was previously discussed with several managers from the executive committee of the company in order to obtain feedback and formal approval before the project start. The decision-making process was facilitated by two academic researchers who are co-authors of this article. Three supervisors and two assistants that are usually concerned about the supply of forklift filters in this company participated to the selection process. A brief description of the participants' profile is provided below:

$>$ Three managers (Head of Production Department, Head of Purchasing Department and Head of Quality Department) with more than 5 years of experience in heavy machine manufacturing.

$>$ Two associate professors from industrial engineering departments with extensive knowledge in decision-making methods, supplier selection, and supply chain management.

$>$ Two assistants (Production assistant and Quality assistant) with extensive knowledge in logistics and experience (> 3 years) in heavy machine manufacturing.

In detail, the facilitators designed the MCDM network model for selecting the most suitable supplier of forklift filters. They also taught participants how to perform the pairwise comparisons in AHP and DEMATEL methods. In addition, they created a set of metrics supporting TOPSIS application. On the other hand, the managers were invited to be involved in the expert group since they can better define the critical needs that must be fulfilled by supplier partners in order to reduce the maintenance costs throughout the supply chain. Finally, the assistants were asked to participate in the MCDM process since they have continuously monitored and analysed the performance of different types of forklift filters during several periods. 


\subsection{Design of the MCDM network model}

The MCDM model was then discussed during two meetings with the participants in order to determine whether it was suitable and comprehensible. The final version of the model is shown in Fig. 2. In this regard, a set of 9 criteria and 29 sub-criteria was defined to rank four potential suppliers ( $\left.S_{1}, S_{2}, S_{3}, S_{4}\right)$. A description of each criterion can be found in Table 3 .

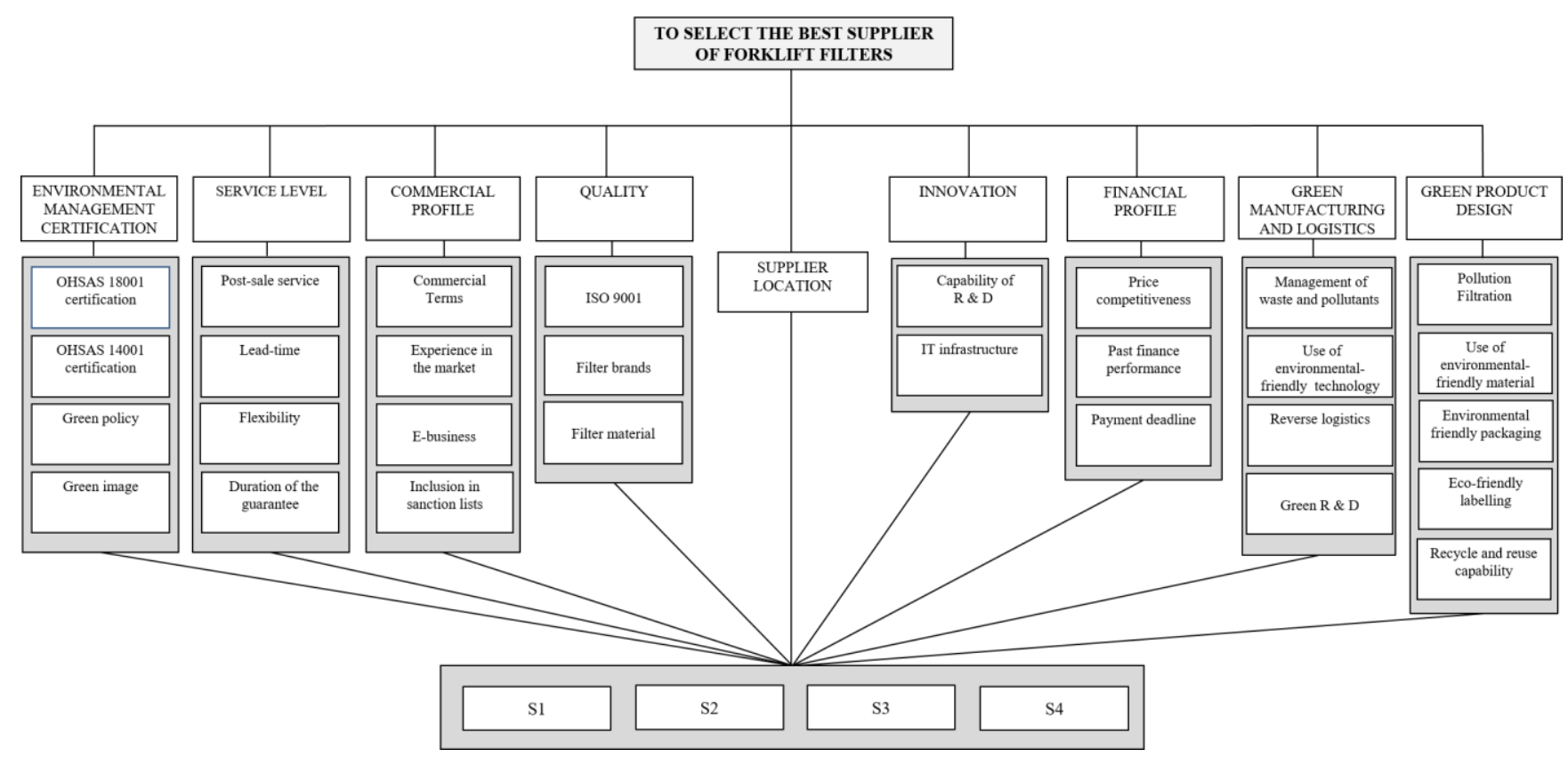

Figure 2. Decision-making hierarchy to select suppliers of forklift filters

Table 3. Description of criteria

\begin{tabular}{|l|l|l|}
\hline \multicolumn{1}{|c|}{ Criterion } & \multicolumn{1}{|c|}{ Sub-criteria } & \multicolumn{1}{c|}{ Criterion description } \\
\hline $\begin{array}{l}\text { Environmental } \\
\text { management } \\
\text { certification (F1) }\end{array}$ & $\begin{array}{l}\text { OHSAS 18001 certification (SF1) } \\
\text { ISO 14001 certification (SF2) } \\
\text { Green policy (SF3) } \\
\text { Green image (SF4) }\end{array}$ & $\begin{array}{l}\text { Evaluates the environmental credentials of potential } \\
\text { suppliers aiming to ensure green procurement best } \\
\text { practice (Bai,Sarkis 2010; Govindan et al. 2015; Shaw et } \\
\text { al. 2012) }\end{array}$ \\
\hline Service level (F2) & $\begin{array}{l}\text { Post-sale service (SF5) } \\
\text { Lead time (SF6) } \\
\text { Flexibility (SF7) } \\
\text { Duration of the guarantee (SF8) } \\
\text { of forklift filters as well as the responsibilities and } \\
\text { priorities in terms of the acceptable service level, the } \\
\text { timetable for delivery, provisions for legal and regulatory } \\
\text { compliance, the adaptability to service demand cycles } \\
\text { and post-sale service (van der Aalst et al. 2008; Amid et } \\
\text { al. 2011) }\end{array}$ \\
\hline $\begin{array}{l}\text { Commercial profile } \\
\text { (F3) }\end{array}$ & $\begin{array}{l}\text { Commercial terms (SF9) } \\
\text { Experience in the market (SF10) } \\
\text { E-business (SF11) } \\
\text { Inclusion in sanction lists (SF12) }\end{array}$ & $\begin{array}{l}\text { Describes the commercial performance of the supplier as } \\
\text { well as the conditions for ordering forklift filters. }\end{array}$ \\
\hline
\end{tabular}




\begin{tabular}{|c|c|c|}
\hline Quality (F4) & $\begin{array}{l}\text { ISO } 9001 \text { (SF13) } \\
\text { Filter brands (SF14) } \\
\text { Filter material (SF15) }\end{array}$ & $\begin{array}{l}\text { Assesses how well the company requirements (referred } \\
\text { to the forklift filters) can be potentially satisfied by the } \\
\text { current quality management system of the supplier. }\end{array}$ \\
\hline Innovation (F5) & $\begin{array}{l}\text { Capability of R\&D (SF16) } \\
\text { IT infrastructure (SF17) }\end{array}$ & $\begin{array}{l}\text { The suppliers also influence the innovation level of } \\
\text { companies. Therefore, it is necessary to determine their } \\
\text { innovation capacity to propel the continuous } \\
\text { improvement programs addressing the correct use of } \\
\text { forklift filters. }\end{array}$ \\
\hline Supplier location (F6) & Without sub-criteria & $\begin{array}{l}\text { Measures the distance between the company and the } \\
\text { potential supplier of forklift filters (Ortiz-Barrios et al. } \\
\text { 2017) }\end{array}$ \\
\hline Financial profile (F7) & $\begin{array}{l}\text { Price competitiveness (SF18) } \\
\text { Past finance performance (SF19) } \\
\text { Payment deadline (SF20) }\end{array}$ & $\begin{array}{l}\text { Determines whether the financial conditions imposed by } \\
\text { the supplier are beneficial for the company while } \\
\text { discarding those providers with poor financial } \\
\text { performance. }\end{array}$ \\
\hline $\begin{array}{l}\text { Green manufacturing } \\
\text { and logistics (F8) }\end{array}$ & $\begin{array}{l}\text { Management of waste and } \\
\text { pollutants (SF21) } \\
\text { Use of environmental-friendly } \\
\text { technology (SF22) } \\
\text { Reverse logistics (SF23) } \\
\text { Green R\&D (SF24) }\end{array}$ & $\begin{array}{l}\text { This criterion determines whether the alternative supplier } \\
\text { has implemented green practices within the design and } \\
\text { production processes of forklift filters. Likewise, it } \\
\text { evaluates if such practices has been also integrated in the } \\
\text { reverse supply chain (Luthra et al. 2017). }\end{array}$ \\
\hline $\begin{array}{l}\text { Green product design } \\
\text { (F9) }\end{array}$ & $\begin{array}{l}\text { Pollution filtration (SF25) } \\
\text { Use of environmental-friendly } \\
\text { material (SF26) } \\
\text { Environmental friendly packaging } \\
\text { (SF27) } \\
\text { Eco-friendly labelling (SF28) } \\
\text { Recycle and reuse capability (SF29) }\end{array}$ & $\begin{array}{l}\text { In this domain, it is intended to establish whether the } \\
\text { main components of forklift filters (i.e. raw material, } \\
\text { packaging, and labelling) are eco-friendly, that is to say } \\
\text { that low impact can be expected along their life cycle } \\
\text { (Kannan et al. 2013; Shen et al. 2013; Orji, Wei 2014; } \\
\text { Luthra et al. 2017; Petrudi et al. 2018) }\end{array}$ \\
\hline
\end{tabular}

In detail, the sub-criteria "OHSAS 18001 CERTIFICATION" and "ISO 14001 CERTIFICATION" evaluate whether the supplier of forklift filters are certified under these norms. In fact, suppliers can improve their image and credibility given the fact that companies search for partners complying with the regulations and having health and safety commitment. On the other hand, "GREEN POLICY" verifies whether the candidate supplier has adopted regulations supporting the reduction of the potential environmental impact derived from its operations (Khan et al. 2018; Guarnieri,Trojan 2019). This is also related to the "GREEN IMAGE" sub-criterion which denotes the number of green seals obtained by the forklift filter supplier due to for its commitment to the environment (Shen et al. 2013; Orji,Wei 2014; Petrudi et al. 2018; Guarnieri,Trojan 2019). Another aspect of interest is "POST-SALE SERVICE" which measures the response time to warranty claims (e.g. indemnification requests). "LEAD TIME" is also considered in this model to evaluate the expected time elapsed between the request and delivery dates. Of course, the shortest time, the better. "FLEXIBILITY" represents the types of forklift filter that can be offered by a supplier in order to support customers when addressing design and demand changes. Attention is also paid to "DURATION OF THE GUARANTEE". In particular, companies from the mining sector are interested in partners providing long warranty periods and giving the choice of extension if needed. This aspect, therefore, becomes a competitive advantage for suppliers during any 
selection process. "COMMERCIAL TERMS" are also included in the supplier selection model since customers are attracted by partners establishing commercial agreements quickly after request. In addition to the aforementioned sub-criteria, "EXPERIENCE IN THE MARKET" has been regarded in this case for determining how stable a supplier is in the business. Given the growing demand, it is necessary to count on with the support of suppliers that can positively collaborate to reduce the bullwhip effect. On the other side, considering the importance of using technology (e.g. inventory reduction, sales augment, financial returns and positive market penetration) for underpinning fast-and-effective commercial supplier-customer relations and transactions, "E-BUSINESS" was also regarded in the MCDM model (Oliveira,Martins 2010). Likewise, it is necessary to verify whether the suppliers had been previously included in sanction lists (SF12) because of an illegal activity (e.g. terrorism financing, narcotics trafficking, human rights violation and money laundering activities) since it will affect the firm reputation and reliability. Furthermore, it is a good practice to take into consideration whether the supplier is ISO 9001 certified to assure it is working with accepted standards and procedures. On the other hand, "FILTER BRANDS" determines the number of forklift filter brands that can be offered by each supplier. Another aspect of importance is "FILTER MATERIAL" which evaluates the durability of each filter material aiming at identifying which is the most suitable for a specific work environment.

The companies from the mining sector have understood that fostering innovation activities requires that suppliers bear more design and development responsibility than before (Wagner 2009). Thus, it is important to determine if the supplier of forklift filters has an R\&D department to support the design and production of innovative heavy machine. Additionally, the partner should count on with IT infrastructure to support supplier-customer collaboration through effective decision-making and efficient information management. These aspects are complemented by financial sub-criteria that should be considered in every supplier selection process: PRICE COMPETITIVENESS, PAST FINANCE PERFORMANCE, and PAYMENT DEADLINE. Specifically, the filter price and payment deadline are critical when companies face different competitors in different markets. Therefore, suppliers offering reasonable prices will be taken into account to increase the competitiveness profile. Besides, it is also relevant to determine the PAST FINANCE PERFORMANCE of the potential partner in order to assess whether its cash flow is able to support the forecasted demand. Thereby, backorders and sanctions can be avoided due to lack of forklift filters.

Other sustainability sub-criteria were considered as part of the supplier selection model. Some of them are associated with the manufacturing and logistics processes of forklift filters. For instance, "MANAGEMENT OF WASTE AND POLLUTANTS" evaluates whether the supplier usually implements protocols for the correct management of waste and pollutants derived from the production of forklift filter (Orji,Wei 2014; Luthra et al. 2017; Petrudi et al. 2018; Guarnieri,Trojan 2019). It is also of paramount to determine if the supplier uses ENVIRONMENTAL-FRIENDLY technology to increase energy efficiency while minimizing harmful waste (Khan et al. 2018). Besides, it is necessary to check if the supplier has implemented a REVERSE LOGISTICS system for collecting the used filters so that potential deterioration of the surrounding environment can be reduced (Petrudi et al. 2018). Likewise, it is useful to verify whether the suppliers consider the potential environmental impact of forklift filters as a critical design requirement and can be therefore concluded as promoters of GREEN R\&D (Ho et al. 2010). On the other hand, there are sustainability aspects specifically inherent to the main components 
of forklift filters. A sub-criterion considered in this category is POLLUTION FILTRATION which measures the maximum filtration capacity of forklift filters (Kannan et al. 2013). In addition, managers should check the use of ENVIRONMENTAL-FRIENDLY MATERIAL to reduce the negative environmental effects of filters after final disposal (Soleimani et al. 2016; Jindal,Sangwan 2017). The use of ENVIRONMENTAL-FRIENDLY PACKAGING is also of interest when selecting sustainable suppliers as suggested by Khan et al. (2018) and Bai et al. (2019). Indeed, alternatives like using raw $100 \%$ recycled materials and creating a circular economy have been proposed to reduce the environmental footprint of packaging. In the meantime, the administrators from the mining sector should also verify the adoption of ECO-FRIENDLY LABELLING in forklift filters. This sub-criterion does not only consider sustainable material choices for labels but eco-friendly practices of label printing companies (Ho et al. 2010). Ultimately, it is also useful to evaluate the RECYCLE and REUSE CAPABILITY of the forklift filters offered by the candidate suppliers. This parameter has been found to be critical when tackling the growing problem posed by waste. In the meantime, as recycle and reuse capability increases, the sustainability and competitiveness of the mining companies also augments considering higher lifecycle of filters and lower replacement costs (Orji,Wei 2014; Lopes de Sousa Jabbour et al. 2018).

\subsection{Linear dependency}

In this study, a data-collection tool was implemented to obtain all the pairwise comparisons required by the FAHP method. The objective of this instrument is to propose an easy-effective way to introduce FAHP to survey respondents who are not skilled in complex mathematics. Thereby, the reliability of the decision-making process can be significantly increased. A survey format (refer to Fig. 3) was designed including the following statement: "How much more important is the element on the left column over the element on the right column?" The survey was filled out by the participants using the three-level scale shown in Table 1. In this table, a fuzzy triangular number is assigned to each level of importance (table 2).

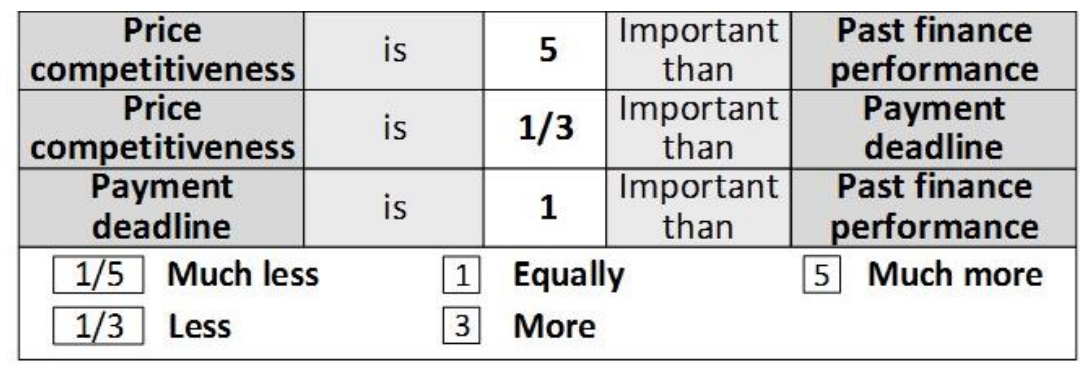

Figure 3. Data-collection tool for FAHP comparisons.

An example of a fuzzy judgment matrix is presented in Table 4, where the data obtained from the survey were added and arranged using Eq. 1-3. Afterwards, the geometric means of fuzzy judgments were calculated for each decision element and the normalized weight values of factors and sub-factors were determined using Eq. 4 and Eq. 5-7 respectively. The resulting global (GW) and local (LW) weights are shown in Table 5. 
Table 4. Fuzzy pairwise comparison matrix for "Environmental profile"

\begin{tabular}{|c|c|c|c|c|}
\hline & SF1 & SF2 & SF3 & SF4 \\
\hline SF1 & {$[1,1,1]$} & {$[0.80,1.18,1.58]$} & {$[1.50,1.89,2.33]$} & {$[0.75,0.78,0.83]$} \\
\hline SF2 & {$[2.08,2.78,3.50]$} & {$[1,1,1]$} & {$[3.33,4.33,5.33]$} & {$[0.75,0.78,0.83]$} \\
\hline SF3 & {$[1.39,2.07,2.75]$} & {$[0.19,0.24,0.33]$} & {$[1,1,1]$} & {$[0.22,0.29,0.50]$} \\
\hline SF4 & {$[1.33,1.67,2.00]$} & {$[1.33,1.67,2.00]$} & {$[2.67,3.67,4.67]$} & {$[1,1,1]$} \\
\hline
\end{tabular}

Table 5. Local and global weights of factors and sub-factors by using FAHP

\begin{tabular}{|l|c|c|}
\hline \multicolumn{1}{|c|}{} & \multicolumn{2}{|c|}{ FAHP } \\
\hline Environmental Management Certification (F1) & $\begin{array}{c}\text { Local } \\
\text { weight }\end{array}$ & $\begin{array}{c}\text { Global } \\
\text { weight }\end{array}$ \\
\hline OHSAS 18001 certification (SF1) & & 0.08 \\
\hline ISO 14001 certification (SF2) & 0.22 & 0.02 \\
\hline Green policy (SF3) & 0.38 & 0.03 \\
\hline Green image (SF4) & 0.23 & 0.02 \\
\hline Service level (F2) & 0.18 & 0.01 \\
\hline Post-sale service (SF5) & & 0.17 \\
\hline Lead time (SF6) & 0.25 & 0.04 \\
\hline Flexibility (SF7) & 0.47 & 0.08 \\
\hline Duration of the guarantee (SF8) & 0.10 & 0.02 \\
\hline Commercial profile (F3) & 0.18 & 0.03 \\
\hline Commercial terms (SF9) & & 0.15 \\
\hline Experience in the market (SF10) & 0.31 & 0.05 \\
\hline E-business (SF11) & 0.37 & 0.06 \\
\hline Inclusion in sanction lists (SF12) & 0.15 & 0.02 \\
\hline Quality (F4) & 0.16 & 0.02 \\
\hline ISO 9001 (SF13) & & 0.18 \\
\hline Filter brands (SF14) & 0.55 & 0.10 \\
\hline Filter material (SF15) & 0.23 & 0.04 \\
\hline Innovation (F5) & 0.23 & 0.04 \\
\hline Capability of R\&O (SF16) & & 0.07 \\
\hline IT infrastructure (SF17) & 0.11 & 0.01 \\
\hline Supplier location (F6) & 0.89 & 0.06 \\
\hline Financial profile (F7) & & 0.10 \\
\hline Price competitiveness (SF18) & & 0.14 \\
\hline Past finance performance (SF19) & 0.65 & 0.09 \\
\hline Payment deadline (SF20) & 0.12 & 0.02 \\
\hline Green manufacturing and logistics (F8) & 0.24 & 0.03 \\
\hline Management of waste and pollutants (SF21) & 0.41 & 0.04 \\
\hline Use of environmental-friendly technology (SF22) & 0.02 \\
\hline Reverse logistics (SF23) & 0.08 & 0.01 \\
\hline Green R\&D (SF24) & 0.41 & 0.02 \\
\hline Green product design (F9) & 0.11 & 0.01 \\
\hline Pollution filtration (SF25) & & 0.07 \\
\hline Use of environmental-friendly material (SF26) & 0.31 & 0.02 \\
\hline Environmental friendly packaging (SF27) & 0.24 & 0.02 \\
\hline Eco-friendly labelling (SF28) & 0.11 & 0.01 \\
\hline Recycle and reuse capability (SF29) & 0.01 \\
\hline
\end{tabular}


The consistency ratios (CR) were also calculated to verify the reliability of comparisons (refer to Table 6). Since $C R$ values are not higher than $10 \%$, the estimated weights can be employed to set the priority ranking of forklift filter suppliers. In this respect, the participants were neither inconsistent nor random when comparing the criteria and sub-criteria. The assessment process can be thus regarded as satisfactory as well as the reduced FAHP scale and survey layout can be further proposed for replication in real-world scenarios.

Table 6. Consistency ratios for fuzzy judgment matrixes

\begin{tabular}{|l|c|}
\hline Factor & Consistency Ratio (CR) \\
\hline Environmental Management Certification & $5.80 \%$ \\
\hline Service level & $2.34 \%$ \\
\hline Commercial profile & $9.36 \%$ \\
\hline Quality & $5.76 \%$ \\
\hline Innovation & $5.62 \%$ \\
\hline Financial profile & $0.00 \%$ \\
\hline Green manufacturing and logistics & $6.98 \%$ \\
\hline Green product design & $0.66 \%$ \\
\hline
\end{tabular}

\subsection{Influence among decision elements}

In this phase, a survey format was also designed to obtain the FDEMATEL pairwise comparisons (refer to Figure 4), which will evidence the influence among factors/sub-factors. For each judgment, it was asked: "how much influence each element on the left exerts over the element on the right?" In this case, the survey respondents answered taking into account the five-point scale shown in Table 2. This process was also repeated until completing all the comparisons.

\begin{tabular}{|c|c|c|c|c|c|c|}
\hline ISO 9001 certification & \multicolumn{2}{|c|}{ Has } & 1 & Influence over & \multicolumn{2}{|r|}{ Filter brands } \\
\hline ISO 9001 certification & \multicolumn{2}{|c|}{ Has } & 3 & Influence over & \multicolumn{2}{|r|}{ Filter material } \\
\hline Filter brands & \multicolumn{2}{|c|}{ Has } & 0 & Influence over & \multicolumn{2}{|r|}{ Filter material } \\
\hline Filter brands & \multicolumn{2}{|c|}{ Has } & 2 & Influence over & \multicolumn{2}{|c|}{ ISO 9001 certification } \\
\hline Filter material & \multicolumn{2}{|c|}{ Has } & 4 & Influence over & \multicolumn{2}{|c|}{ ISO 9001 certification } \\
\hline Filter material & \multicolumn{2}{|c|}{ Has } & 1 & Influence over & \multicolumn{2}{|r|}{ Filter brands } \\
\hline 0 No & & 2 & \multicolumn{2}{|c|}{ Medium } & \multirow[t]{2}{*}{4} & \multirow[t]{2}{*}{ Very high } \\
\hline 1 Low & & 3 & High & & & \\
\hline
\end{tabular}

Figure 4. Data-collection tool for FDEMATEL comparisons

Then, the pairwise fuzzy judgments were computed by implementing Eq. 8-11. An example of a fuzzy direct-influence matrix $\widetilde{\boldsymbol{D}}$ is shown in Table 7. After applying Eq. 12, the normalized fuzzy direct-relation matrix $\widetilde{\boldsymbol{N}}$ is presented in Table 8. Finally, the fuzzy matrix is obtained using Eq. 13 shows in Table 9. 
Table 7. Fuzzy direct-influence matrix for "Environmental Management Certification"

\begin{tabular}{|c|c|c|c|c|c|c|c|c|}
\hline & SF1 & SF2 & SF3 & SF4 & $\sum_{j=1}^{n} l_{i j}^{(k)}$ & $\sum_{j=1}^{n} m_{i j}^{(k)}$ & $\sum_{j=1}^{n} u_{i j}^{(k)}$ & $r^{(k)}$ \\
\hline SF1 & {$[0.00,0.00,0.25]$} & {$[0.25,0.50,0.75]$} & {$[0.00,0.25,0.50]$} & {$[0.00,0.08,0.33]$} & 0.25 & 0.83 & 1.83 & \multirow{4}{*}{2.5} \\
\hline SF2 & {$[0.00,0.25,0.50]$} & {$[0.00,0.00,0.25]$} & {$[0.50,0.75,0.50]$} & {$[0.75,1.00,0.92]$} & 1.25 & 2.00 & 2.17 & \\
\hline SF3 & {$[0.00,0.08,0.33]$} & {$[0.42,0.67,0.92]$} & {$[0.00,0.00,0.25]$} & {$[0.67,0.92,1.00]$} & 1.09 & 1.67 & 2.50 & \\
\hline SF4 & {$[0.00,0.00,0.25]$} & {$[0.42,0.67,0.92]$} & {$[0.05,0.75,1.00]$} & {$[0.00,0.00,0.25]$} & 0.92 & 1.42 & 2.42 & \\
\hline
\end{tabular}

Table 8. Normalized fuzzy direct-relation matrix for "Environmental Management Certification"

SF1

\begin{tabular}{l|l|l|l|l|} 
SF1 & {$[0.00,0.00,0.10]$} & {$[0.10,0.20,0.30]$} & {$[0.00,0.10,0.20]$} & {$[0.00,0.03,0.13]$} \\
\hline SF2 & {$[0.00,0.10,0.20]$} & {$[0.00,0.00,0.10]$} & {$[0.20,0.30,0.20]$} & {$[0.30,0.40,0.37]$} \\
SF3 & {$[0.00,0.03,0.13]$} & {$[0.17,0.27,0.37]$} & {$[0.00,0.00,0.10]$} & {$[0.27,0.37,0.40]$} \\
\hline SF4 & {$[0.00,0.00,0.10]$} & {$[0.17,0.27,0.37]$} & {$[0.20,0.30,0.40]$} & {$[0.00,0.00,0.10]$}
\end{tabular}

Table 9. The fuzzy total influence matrix for "Environmental Management Certification"

\begin{tabular}{|c|c|c|c|c|c|}
\hline & SF1 & SF2 & SF3 & SF4 & $\check{\mathbf{R}}$ \\
\hline SF1 & {$[0.00,0.05,1.22]$} & {$[0.11,0.37,2.51]$} & {$[0.03,0.30,2.06]$} & {$[0.04,0.29,2.27]$} & {$[0.18,1.01,8.06]$} \\
\hline SF2 & {$[0.00,0.17,1.52]$} & {$[0.12,0.45,2.79]$} & {$[0.31,0.70,2.45]$} & {$[0.42,0.84,2.86]$} & {$[0.85,2.16,9.63]$} \\
\hline SF3 & {$[0.00,0.11,1.66]$} & {$[0.25,0.61,3.41]$} & {$[0.13,0.43,2.69]$} & {$[0.38,0.77,3.28]$} & {$[0.76,1.91,11.04]$} \\
\hline SF4 & {$[0.00,0.08,1.61]$} & {$[0.24,0.57,3.34]$} & {$[0.28,0.62,2.87]$} & {$[0.15,0.46,2.99]$} & {$[0.66,1.72,10.82]$} \\
\hline$\check{\boldsymbol{C}}$ & {$[0.00,0.40,6.02]$} & {$[0.73,2.00,12.05]$} & {$[0.74,2.05,10.08]$} & {$[0.98,2.37,11.40]$} & \\
\hline
\end{tabular}

The prominence $\left(\tilde{C}_{i}+\tilde{R}_{j}\right)$ and relation $\left(\tilde{C}_{i}-\tilde{R}_{j}\right)$ measures are obtained through $\tilde{C}_{i}$ and $\tilde{R}_{j}$ values illustrated in Table 10. Also, the receivers and dispatchers were indicated in Table 10. The results show that Commercial profile (F4) has the highest positive $C+R$ value (6.14), indicating that is the principal generator of effects and the most influencing factor when selecting the best supplier of forklift filters. Therefore, Commercial profile (F4) should be prioritized by the suppliers to improve its performance. This finding is also stressed out by Foss,Jensen (2019) who concluded that the entire organizational structure of suppliers should be properly aligned to their commercial profile so that effective response can be provided to supply chain partners.

Table 10. Dispatchers and receivers in the decision-making model

\begin{tabular}{|l|c|c|c|c|}
\hline & C $+\mathbf{R}$ & $\mathbf{C}-\mathbf{R}$ & Dispatcher & Receiver \\
\hline Environmental Management Certification (F1) & 5.10 & -0.04 & & $\mathrm{X}$ \\
\hline OHSAS 18001 certification (SF1) & 3.62 & -15.33 & & $\mathrm{X}$ \\
\hline ISO 14001 certification (SF2) & 7.06 & 0.27 & $\mathrm{X}$ & \\
\hline Green policy (SF3) & 6.82 & 2.35 & $\mathrm{X}$ & \\
\hline Green image (SF4) & 7.09 & 0.57 & $\mathrm{X}$ & \\
\hline Service level (F2) & 4.97 & 0.63 & $\mathrm{X}$ & \\
\hline Post-sale service (SF5) & -8.96 & 19.64 & $\mathrm{X}$ & \\
\hline Lead time (SF6) & -8.90 & -0.01 & & $\mathrm{X}$ \\
\hline Flexibility (SF7) & -8.67 & 0.76 & $\mathrm{X}$ & \\
\hline Duration of the guarantee (SF8) & -8.91 & 0.18 & $\mathrm{X}$ & \\
\hline Commercial profile (F3) & 6.14 & 0.84 & $\mathrm{X}$ & \\
\hline
\end{tabular}




\begin{tabular}{|l|c|c|c|c|}
\hline Commercial terms (SF9) & 2.41 & 0.23 & $\mathrm{X}$ & \\
\hline Experience in the market (SF10) & 2.82 & 41.26 & $\mathrm{X}$ & \\
\hline E-business (SF11) & 2.40 & 0.30 & $\mathrm{X}$ & \\
\hline Inclusion in sanction lists (SF12) & 1.77 & -0.19 & & $\mathrm{X}$ \\
\hline Quality (F4) & 4.82 & 0.33 & $\mathrm{X}$ & \\
\hline ISO 9001 (SF13) & 5.08 & 0.14 & $\mathrm{X}$ & \\
\hline Filter brands (SF14) & 5.93 & 0.02 & $\mathrm{X}$ & \\
\hline Filter material (SF15) & 6.19 & 1.48 & $\mathrm{X}$ & \\
\hline Innovation (F5) & 5.51 & -0.33 & & $\mathrm{X}$ \\
\hline Capability of R\&O (SF16) & 10.83 & -6.77 & & $\mathrm{X}$ \\
\hline IT infrastructure (SF17) & 10.83 & 0.38 & $\mathrm{X}$ & \\
\hline Supplier location (F6) & 2.84 & -0.26 & & $\mathrm{X}$ \\
\hline Financial profile (F7) & 5.44 & -0.15 & & $\mathrm{X}$ \\
\hline Price competitiveness (SF18) & 4.90 & 0.60 & $\mathrm{X}$ & \\
\hline Past finance performance (SF19) & 5.95 & 0.91 & $\mathrm{X}$ & \\
\hline Payment deadline (SF20) & 5.82 & 69.01 & $\mathrm{X}$ & \\
\hline Green manufacturing and logistics (F8) & 3.15 & -0.07 & & $\mathrm{X}$ \\
\hline Management of waste and pollutants (SF21) & 20.79 & 0.12 & $\mathrm{X}$ & \\
\hline Use of environmental-friendly technology (SF22) & 19.16 & 0.76 & $\mathrm{X}$ & \\
\hline Reverse logistics (SF23) & 20.18 & 0.11 & $\mathrm{X}$ & \\
\hline Green R\&D (SF24) & 20.37 & 1.10 & $\mathrm{X}$ & \\
\hline Green product design (F9) & 3.26 & 1.77 & $\mathrm{X}$ & \\
\hline Pollution filtration (SF25) & 4.43 & 0.10 & $\mathrm{X}$ & \\
\hline Use of environmental-friendly material (SF26) & 6.11 & -2.06 & & $\mathrm{X}$ \\
\hline Environmental friendly packaging (SF27) & 5.24 & 0.12 & $\mathrm{X}$ & \\
\hline Eco-friendly labelling (SF28) & 4.76 & 0.11 & $\mathrm{X}$ & \\
\hline Recycle and reuse capability (SF29) & 5.72 & -1.81 & & $\mathrm{X}$ \\
\hline
\end{tabular}

The correlation among sub-factors of each cluster was analysed adopting impact-digraph maps (Figure 5 to 6). The blue arrows represent one-direction influences whilst the orange ones denote feedback relationships. The impact-diagram map for factors is shown in Figures 5a-5i. In this case, the threshold value was set as $p=\frac{22.784}{9^{2}}=0.281$ after defuzzifying the corresponding matrix $\widetilde{\boldsymbol{T}}$. It can be mentioned that Quality (F4), Innovation (F5) and Green product design (F9) are receivers and the other criteria are dispatchers. Thus, the potential suppliers have to demonstrate its commitment to quality by providing adequate resources, which is accomplished through investments, effective process control, and suitable monitoring. On a different tack, the presence of F5 and F9 among the first-ranked factors evidence the current need for partnering with suppliers designing, producing, and delivering innovative and ecofriendly forklift filters so that future sustainability in the market can be fully granted while reducing the carbon footprint associated with the lifecycle of this product. 


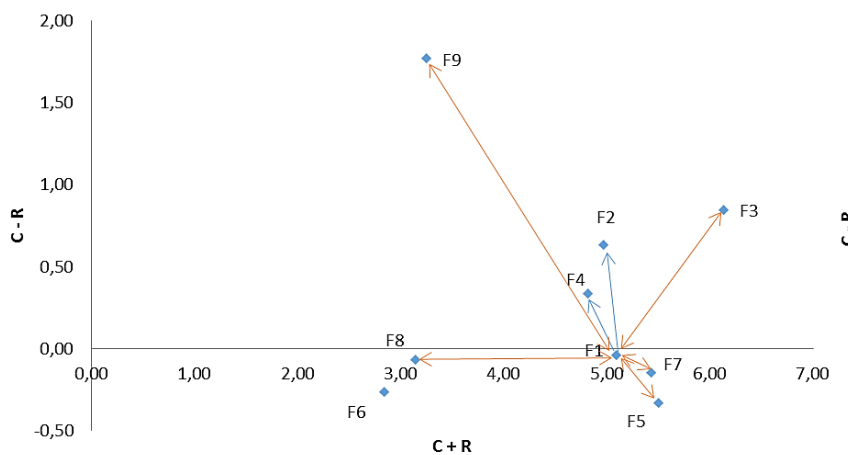

(a)

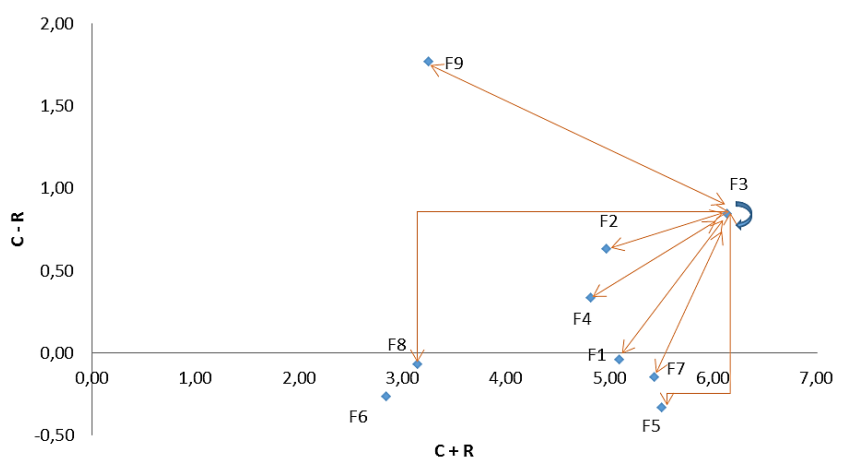

(c)

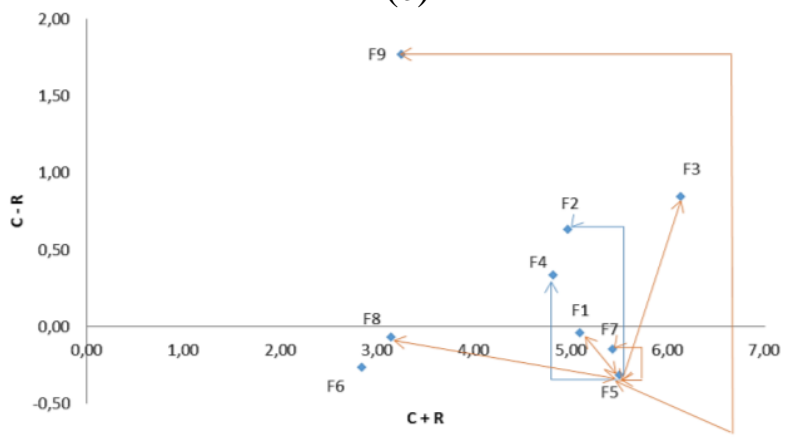

(e)

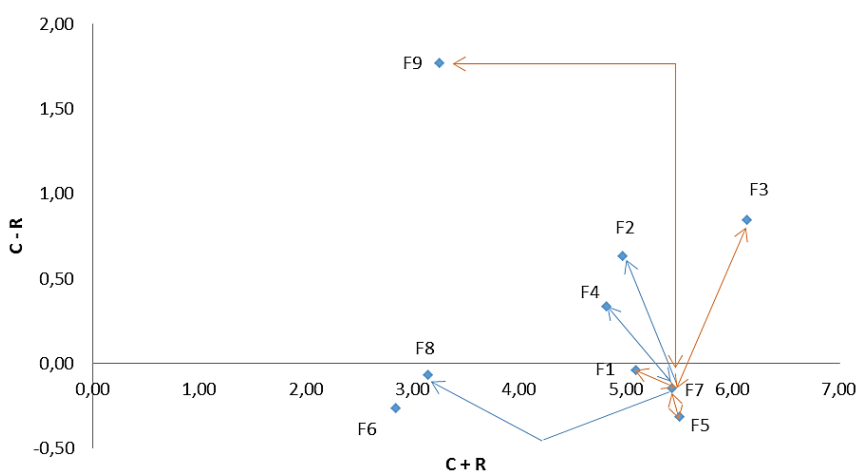

(g)

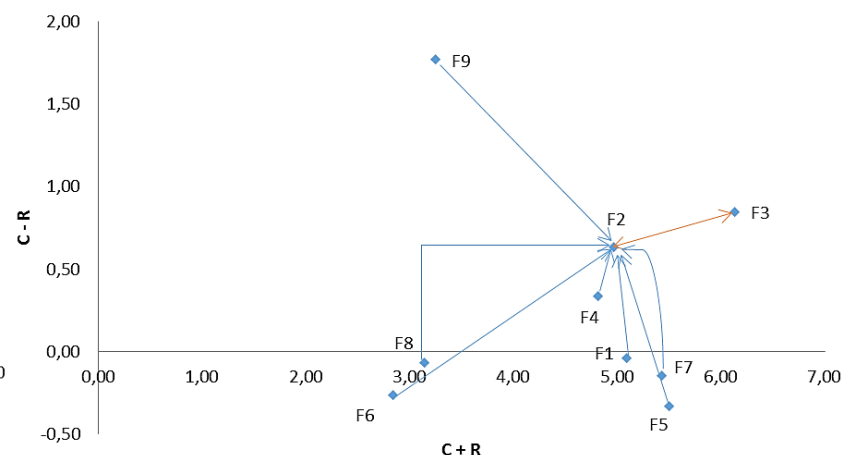

(b)

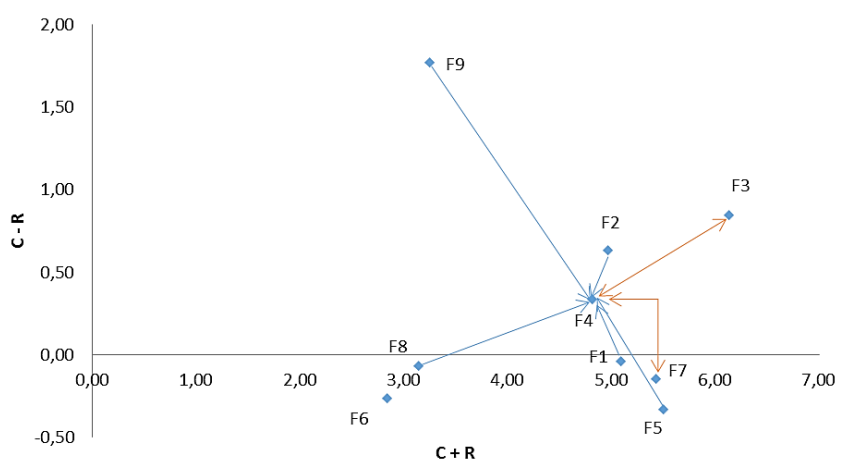

(d)

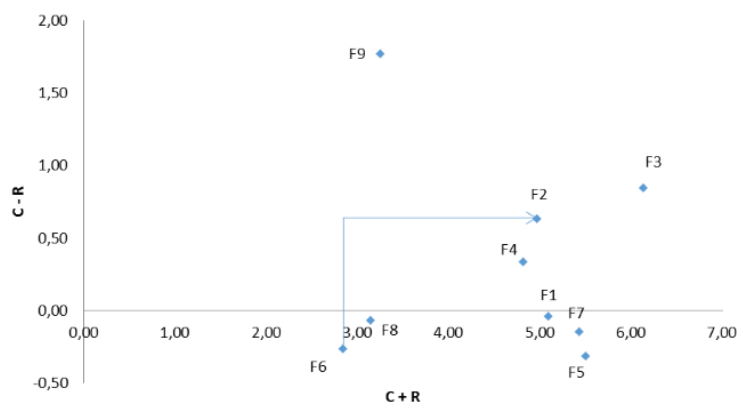

(f)

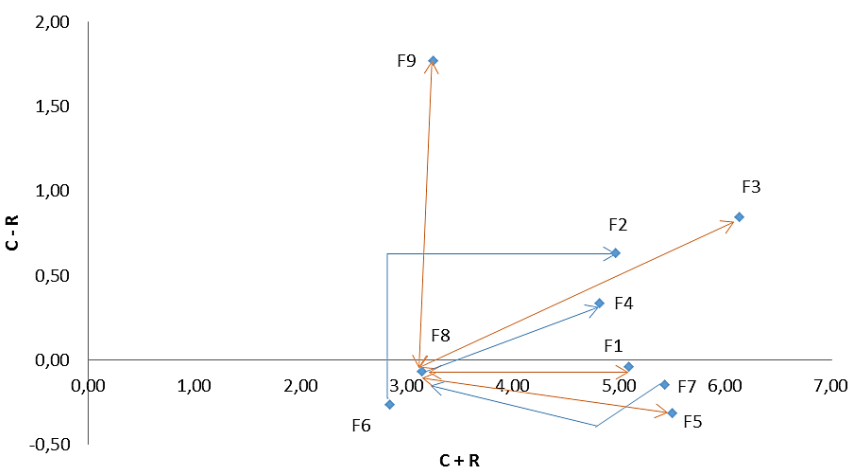

(h) 


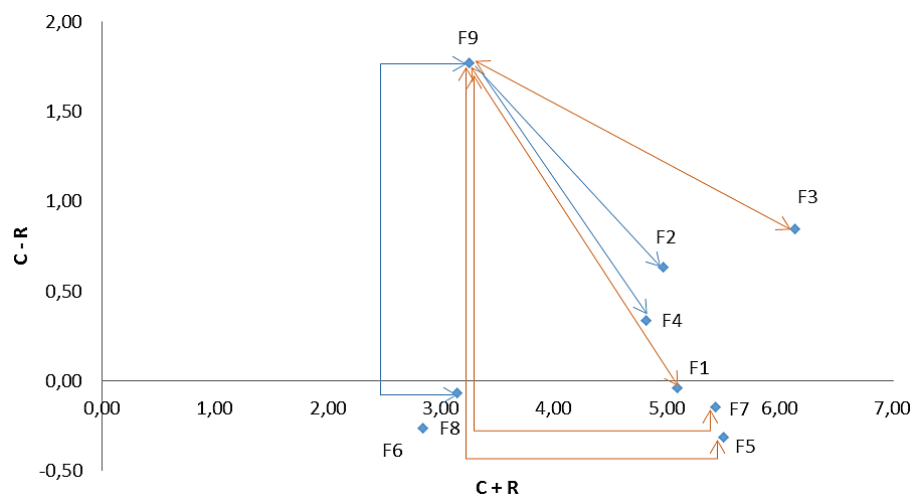

(i)

Figure 5. Impact-Diagram map for factors: a) Environmental management certification (F1), b) Service level (F2), c) Commercial profile (F3), d) Quality (F4), e) Innovation (F5), f) Supplier location (F6), g) Financial profile (F7), h) Green manufacturing and logistics (F8), and i) Green product design (F9).

On the other hand, impact-digraph maps for the environmental management certification (Figure 6a) and commercial profile (Figure 6b) are shown as examples of how to evaluate interrelations among subcriteria. In this category, the assigned threshold value was set as $p=\frac{12.318}{4^{2}}=0.770$. As a result, ISO 14001 certification (SF2), Green policy (SF3) and Green image (SF4) were classified as dispatchers; whilst $O S H A S 18001$ certification (SF1) was considered as a receiver. In this respect, SF2, SF3, and SF4 aim to bring a company into alignment with its environmental policy, a primary goal of OHSAS 18001, so that the consequences on the environment can be at least minimized. A growing consensus among suppliers of forklift filters and mining companies is then needed for greater environmental responsiveness (Fryxell,Szeto 2002). Besides, no causal relationships were identified between (SF1) and the rest of F1 sub-factors.

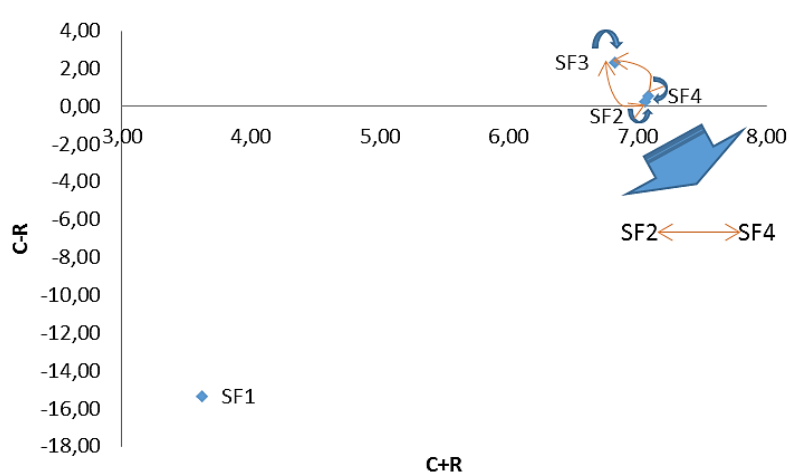

(a)

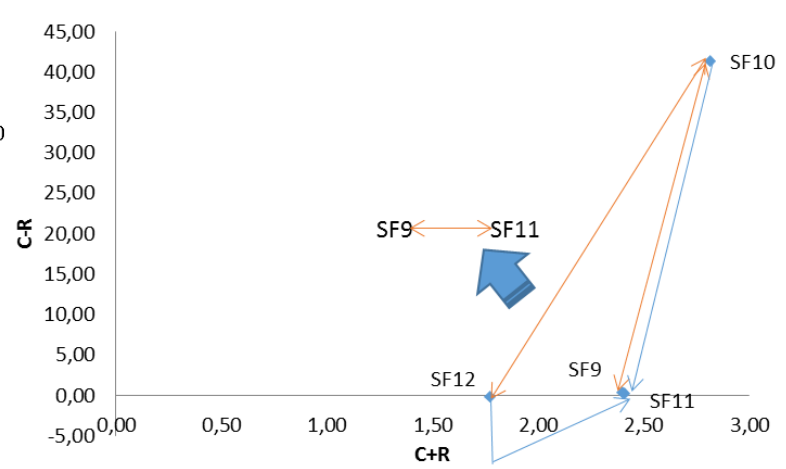

(b)

Figure 6. Impact-Diagram map for a) Environmental management certification and b) Commercial profile

Also, the $(D+R, D-R)$ data set was mapped for commercial profile sub-criteria (Figure 6b). The established threshold value was set as $p=\frac{4.508}{4^{2}}=0.282$. In this case, Commercial terms (SF9), Experience in the market (SF10) and E-business (SF11) were classified as dispatchers and Inclusion in sanction lists (SF12) was considered as a receiver. In particular, E-business has been found to streamline 
processes and integrate the supply chain, which ends up reducing logistic costs (Gunasekaran et al. 2008). On the other side, experienced suppliers provide stability to the company since they fully know the market demands and could effectively contribute to the design of customer-oriented heavy machinery. Besides, it can be viewed that (SF10) is affected by (SF9) and vice versa. This relation was also observed between $S F 11$ and SF9.

\subsection{Final criteria and sub-criteria weights: Integrating FAHP and FDEMATEL}

Using Eq. 24-26, the relative weights of criteria and sub-criteria on the basis of interdependence were calculated. Table 11 summarizes the global and local contributions of each decision element after integrating FAHP and FDEMATEL methods.

Table 11. Local and global weights for criteria and sub-criteria under FAHP-FDEMATEL hybrid method

\begin{tabular}{|c|c|c|}
\hline & \multicolumn{2}{|c|}{ FAHP-FDEMATEI } \\
\hline & $\begin{array}{c}\text { Local } \\
\text { weight }\end{array}$ & $\begin{array}{l}\text { Global } \\
\text { weight }\end{array}$ \\
\hline Environmental Management certification (F1) & & 0.10 \\
\hline OHSAS 18001 certification (SF1) & 0.35 & 0.04 \\
\hline ISO 14001 certification (SF2) & 0.28 & 0.03 \\
\hline Green policy (SF3) & 0.29 & 0.03 \\
\hline Green image (SF4) & 0.08 & 0.01 \\
\hline Service level (F2) & & 0.17 \\
\hline Post-sale service (SF5) & 0.69 & 0.12 \\
\hline Lead time (SF6) & 0.15 & 0.03 \\
\hline Flexibility (SF7) & 0.11 & 0.02 \\
\hline Duration of the guarantee (SF8) & 0.06 & 0.01 \\
\hline Commercial profile (F3) & & 0.19 \\
\hline Commercial terms (SF9) & 0.06 & 0.01 \\
\hline Experience in the market (SF10) & 0.89 & 0.17 \\
\hline E-business (SF11) & 0.03 & 0.01 \\
\hline Inclusion in sanction lists (SF12) & 0.02 & 0.01 \\
\hline Quality (F4) & & 0.13 \\
\hline ISO 9001 (SF13) & 0.50 & 0.07 \\
\hline Filter brands (SF14) & 0.24 & 0.03 \\
\hline Filter material (SF15) & 0.26 & 0.03 \\
\hline Innovation (F5) & & 0.20 \\
\hline Capability of R\&O (SF16) & 0.13 & 0.03 \\
\hline IT infrastructure (SF17) & 0.87 & 0.17 \\
\hline Supplier location (F6) & & 0.04 \\
\hline Financial profile (F7) & & 0.08 \\
\hline Price competitiveness (SF18) & 0.25 & 0.02 \\
\hline Past finance performance (SF19) & 0.11 & 0.01 \\
\hline Payment deadline (SF20) & 0.64 & 0.05 \\
\hline Green manufacturing and logistics (F8) & & 0.03 \\
\hline Management of waste and pollutants (SF21) & 0.41 & 0.01 \\
\hline Use of environmental-friendly technology (SF22) & 0.08 & 0.01 \\
\hline Reverse logistics (SF23) & 0.40 & 0.01 \\
\hline Green R\&D (SF24) & 0.11 & 0.01 \\
\hline Green product design (F9) & & 0.05 \\
\hline
\end{tabular}




\begin{tabular}{|l|l|l|}
\hline Pollution filtration (SF25) & 0.25 & 0.01 \\
\hline Use of environmental-friendly material (SF26) & 0.28 & 0.01 \\
\hline Environmental friendly packaging (SF27) & 0.11 & 0.01 \\
\hline Eco-friendly labelling (SF28) & 0.05 & 0.01 \\
\hline Recycle and reuse capability (SF29) & 0.31 & 0.02 \\
\hline
\end{tabular}

According to FAHP-FDEMATEL results, Innovation was the criterion with the highest priority $(\mathrm{GW}=$ 0.17 ) when selecting providers of forklift filters. In addition, there is not a significant difference $(0.01)$ between Innovation ( $1^{\text {st }}$ place) and Commercial profile ( $2^{\text {nd }}$ place). Hence, these suppliers need to focus on improving these criteria primarily in order to be attractive to manufacturing companies from the mining industry. This is directly related to the high-quality standards required by final customers (e.g. construction firms) when acquiring this type of equipment. Of course, given the multi-criteria nature of this decision, the providers cannot discard the rest of the criteria, which should be continuously evaluated for continuous revision and improvement. In Quality cluster, the most important sub-criterion was ISO 9001 ( $\mathrm{LW}=0.5$ ). This certification was found to be a credible public signal of effective quality management practices in addition to supporting compliance with regulatory and customer requirements (Castka 2018; Blind et al. 2018). Besides, ISO 9001 is considered valuable for standardizing suppliers' processes, which can reduce logistics costs and augment the number of forklift filters conform to specifications.

In Innovation cluster, the most relevant sub-criterion was IT infrastructure (LW $=0.87$ ). In this respect, the suppliers should be prepared to effectively contribute to joint process engineering and the design of new heavy machinery through continuous innovation processes responding to the current market needs. It is therefore important that suppliers of forklift filters invest in IT infrastructure to achieve better product performance, reduced development costs and shorter time to market (Lau et al. 2010). The result of efficient supplier-firm integration is then a set of best practices that can be rapidly deployed within the company using suitable IT infrastructure ensuring information sharing and product co-development. In the Service level domain, Post-sale service was the most crucial element ( $\mathrm{LW}=0.69)$. Companies from the mining industry need suppliers providing support services during the life cycle of forklift filters. This implies collecting the returned filters and repairing/replacing the defective units. Inefficient postsale service may contribute to higher work-in-process inventory, increased number of backorders and cost overruns. For this purpose, firms from this industry are very interested in collaborating with providers having a Post-sale service that can continuously support their operations. Thereby, their supply chain can be more efficient when facing seasonal demand peaks and increasing sales.

Regarding Commercial profile cluster, Experience in the market ( $\mathrm{LW}=0.89$ ) was the most representative sub-criterion. Mining companies usually export to European, American and Asian markets, which are increasingly demanding with respect to consumption volume and the compliance of quality requirements. To gain a competitive advantage in these markets, experienced suppliers of forklift filters are highly required. These providers play a pivotal role when ensuring the promised machine's lifetime since they fully know the earthwork operations it will perform. They can then design filters effectively removing the contaminants that can be found in the above-mentioned markets so that the engine combustion system can be protected. The reputation of these companies is also acknowledged by international customers and has become a key aspect for deal closing. Finally, although other sub-criteria were taken into account 
in the supplier selection model, their global contribution to the final decision was not significant $(\mathrm{GW}<$ $10 \%)$.

\subsection{TOPSIS method}

This phase presents the implementation of the TOPSIS method whose primary aim is to rank the potential suppliers of forklift filters. In addition, the sub-criteria most contributing to the total separation of each supplier can be identified so that improvement strategies can be effectively designed and implemented. First, a metric (Table 12) was defined per each sub-criterion (also for Supplier selection criterion since it has no sub-elements). Then, using Eq. 27, TOPSIS decision matrix D was achieved (Table 13) where suppliers of forklift filters $\left(S_{1}, S_{2}, S_{3}, S_{4}\right)$ were related to the sub-factors. Sub-factors' values were computed taking into account the description shown in Table 12.

Table 12: KPIs for sub-criteria

\begin{tabular}{|c|c|c|c|}
\hline Sub-criterion & Metric & & Formula \\
\hline $\begin{array}{l}\text { OHSAS } 18001 \\
\text { certification }\end{array}$ & $\begin{array}{c}\text { OHSAS } 18001 \\
\text { certification status }\end{array}$ & & If certified $(1)$, otherwise $(0)$ \\
\hline $\begin{array}{l}\text { ISO } 14001 \\
\text { certification }\end{array}$ & $\begin{array}{c}\text { ISO } 14001 \\
\text { certification status }\end{array}$ & & If certified (1), otherwise (0) \\
\hline Green policy & $\begin{array}{c}\text { Existence of green } \\
\text { policies }\end{array}$ & & If available (1), otherwise (0) \\
\hline Green image & $\begin{array}{c}\text { Number of green } \\
\text { seals } \\
\end{array}$ & \multicolumn{2}{|c|}{ Number of green seals obtained by the forklift filter supplier } \\
\hline $\begin{array}{l}\text { Post-sale } \\
\text { service }\end{array}$ & $\begin{array}{l}\text { Average lead time } \\
\text { for complaint } \\
\text { response }\end{array}$ & $\sum_{i=1}^{n} \frac{R S D_{i}-R D_{i}}{n}$ & $\begin{array}{l}R S D_{i}: \text { response date of complaint } i \\
R D_{i}: \text { receipt date of complaint } i \\
n: \text { number of complaints in a year }\end{array}$ \\
\hline Lead time & $\begin{array}{l}\text { Average lead time } \\
\text { for order delivery }\end{array}$ & $\sum_{i=1}^{n} \frac{D D_{i}-R D_{i}}{n}$ & $\begin{array}{l}D D_{i}: \text { delivery date of order } i \\
R D_{i}: \text { request date of order } i \\
n: \text { number of orders in a year }\end{array}$ \\
\hline Flexibility & $\begin{array}{l}\text { Flexible product } \\
\text { offer }\end{array}$ & \multicolumn{2}{|r|}{ Number of forklift filters offered } \\
\hline $\begin{array}{l}\text { Duration of the } \\
\text { guarantee }\end{array}$ & Warranty length & \multicolumn{2}{|r|}{ Number of years warranty } \\
\hline $\begin{array}{l}\text { Commercial } \\
\text { terms }\end{array}$ & $\begin{array}{l}\text { Average lead time } \\
\text { for the } \\
\text { establishment of } \\
\text { commercial } \\
\text { contract }\end{array}$ & $\sum_{i=1}^{n} \frac{S D_{i}-R D_{i}}{n}$ & $\begin{array}{l}S D_{i}: \text { signature date of commercial contract } i \\
R D_{i}: \text { request date of commercial contract } i \\
n: \text { number of commercial contracts requested in a year }\end{array}$ \\
\hline $\begin{array}{l}\text { Experience in } \\
\text { the market }\end{array}$ & Supplier lifespan & \multicolumn{2}{|r|}{ Years of market experience } \\
\hline E-business & $\begin{array}{l}\text { Availability of E- } \\
\text { business platform }\end{array}$ & \multicolumn{2}{|r|}{ If available (1), otherwise (0) } \\
\hline $\begin{array}{l}\text { Inclusion in } \\
\text { sanction lists }\end{array}$ & $\begin{array}{l}\text { Inclusion in } \\
\text { COFAC/INTERPOL } \\
\text { list } \\
\end{array}$ & \multicolumn{2}{|r|}{ If included (1), otherwise (2) } \\
\hline $\begin{array}{l}\text { ISO } 9001 \\
\text { certification }\end{array}$ & $\begin{array}{c}\text { ISO } 9001 \\
\text { certification status }\end{array}$ & \multicolumn{2}{|r|}{ If certified (1), otherwise $(0)$} \\
\hline
\end{tabular}




\begin{tabular}{|c|c|c|}
\hline Filter brands & Variety of brands & Number of forklift filter brands offered by the supplier \\
\hline Filter material & Filter durability & Number of operating hours of the filter \\
\hline $\begin{array}{l}\text { Capability of } \\
\text { R\&D }\end{array}$ & $\begin{array}{l}\text { Availability of } \\
\text { R\&D department }\end{array}$ & If available $(1)$, otherwise $(0)$ \\
\hline $\begin{array}{l}\text { IT } \\
\text { infrastructure }\end{array}$ & $\begin{array}{c}\text { Availability of } \\
\text { Decision Support } \\
\text { Systems }\end{array}$ & If available (1), otherwise (0) \\
\hline $\begin{array}{l}\text { Supplier } \\
\text { location }\end{array}$ & Proximity & Distance (in km) between the company and the potential supplier \\
\hline $\begin{array}{l}\text { Price } \\
\text { competitiveness }\end{array}$ & Price & Price per forklift filter \\
\hline $\begin{array}{l}\text { Past finance } \\
\text { performance }\end{array}$ & $\begin{array}{c}\text { Return on } \\
\text { Investment (2016) }\end{array}$ & $\frac{\text { Net profit }(2016)}{\text { Total investment }(2016)} * 100$ \\
\hline $\begin{array}{l}\text { Payment } \\
\text { deadline }\end{array}$ & Payment period & Time (in days) between delivery date and requested payment day \\
\hline $\begin{array}{l}\text { Management of } \\
\text { waste and } \\
\text { pollutants }\end{array}$ & $\begin{array}{l}\text { Existence of } \\
\text { protocols for the } \\
\text { management of } \\
\text { waste and } \\
\text { pollutants }\end{array}$ & If available (1), otherwise (0) \\
\hline $\begin{array}{l}\text { Use of } \\
\text { environmental- } \\
\text { friendly } \\
\text { technology }\end{array}$ & $\begin{array}{l}\text { Availability of eco- } \\
\text { friendly technology } \\
\text { for forklift filter } \\
\text { production }\end{array}$ & If available (2), otherwise (1) \\
\hline $\begin{array}{l}\text { Reverse } \\
\text { logistics }\end{array}$ & $\begin{array}{l}\text { Availability of a } \\
\text { reverse logistics } \\
\text { system for forklift } \\
\text { filter collection }\end{array}$ & If available (1), otherwise (0) \\
\hline Green R\&D & Green-based design & $\begin{array}{l}\text { If the supplier considers the environmental impact of its forklift filter during the } \\
\text { design process }(1) \text {, otherwise }(0)\end{array}$ \\
\hline $\begin{array}{l}\text { Pollution } \\
\text { filtration }\end{array}$ & $\begin{array}{l}\text { Maximum filtration } \\
\text { capacity }\end{array}$ & $\frac{p p m \text { of filtered particulate material }}{\text { ppm of input particulate material }} * 100$ \\
\hline $\begin{array}{l}\text { Use of } \\
\text { environmental- } \\
\text { friendly } \\
\text { material }\end{array}$ & $\begin{array}{l}\text { Eco-friendly } \\
\text { composition }\end{array}$ & $\begin{array}{l}\text { If eco-friendly material is used as the main component of forklift filters (1), } \\
\text { otherwise (0) }\end{array}$ \\
\hline $\begin{array}{l}\text { Environmental } \\
\text { friendly } \\
\text { packaging }\end{array}$ & $\begin{array}{l}\text { Eco-friendly } \\
\text { packaging }\end{array}$ & If eco-friendly material is used for filter packaging (1), otherwise (0) \\
\hline $\begin{array}{l}\text { Eco-friendly } \\
\text { labelling }\end{array}$ & $\begin{array}{l}\text { Environmental- } \\
\text { friendly labelling }\end{array}$ & If eco-friendly material is used for filter labelling (1), otherwise (0) \\
\hline $\begin{array}{l}\text { Recycle and } \\
\text { reuse capability }\end{array}$ & $\begin{array}{l}\text { Recycle/Reuse } \\
\text { capability }\end{array}$ & If the filter can be recycled or reused (2), otherwise (1) \\
\hline
\end{tabular}

Positive $\left(A^{+}\right)$and reverse $\left(A^{-}\right)$extreme performances were also defined in Tables 13a-13b using Eq. 31 and Eq. 32 respectively. The normalized TOPSIS decision matrix $N$ is shown in Tables 14a-14b applying Eq. 28-29. The weighted and normalized TOPSIS decision matrix $T$ (Tables 15a-15b) was achieved using Eq. 30. The sub-factors' contributions were determined through the hybrid FAHP-FDEMATEL method. Whilst, the separation of each supplier alternative $\left(S_{1}, S_{2}, S_{3}, S_{4}\right)$ from the positive ideal solution $\left(S_{i}^{+}\right)$is inserted in Table 16 after applying Eq. 33. In addition, the contribution of each sub-factor to the total 
separation from PIS is specified in this table. Similarly, the separation of each supplier from the negative ideal scenario $\left(S_{i}^{-}\right)$is calculated using Eq. 34 (refer to Table 17).

Table 13a. TOPSIS decision matrix $D$ for selecting suppliers of forklift filters

\begin{tabular}{|c|c|c|c|c|c|c|c|c|c|c|c|c|c|c|}
\hline & SF1 & SF2 & SF3 & SF4 & SF5 & SF6 & SF7 & SF8 & SF9 & SF10 & SF11 & SF12 & SF13 & SF14 \\
\hline S1 & 1 & 1 & 1 & 1 & 0 & 3 & 100 & 2 & 1 & 21 & 0 & 1 & 1 & 5 \\
\hline S2 & 1 & 1 & 1 & 1 & 3 & 5 & 100 & 1 & 1 & 42 & 0 & 1 & 1 & 3 \\
\hline S3 & 1 & 1 & 1 & 1 & 3 & 6 & 100 & 1 & 1 & 39 & 1 & 1 & 1 & 5 \\
\hline S4 & 1 & 1 & 1 & 1 & 1 & 4 & 100 & 1 & 1 & 20 & 1 & 1 & 1 & 5 \\
\hline $\mathrm{A}+$ & 1 & 1 & 1 & 2 & 0 & 3 & 100 & 2 & 1 & 42 & 1 & 2 & 1 & 5 \\
\hline A- & 0 & 0 & 0 & 1 & 3 & 6 & 0 & 1 & 0 & 20 & 0 & 1 & 0 & 3 \\
\hline W & 0.037 & 0.029 & 0.031 & 0.008 & 0.118 & 0.025 & 0.018 & 0.010 & 0.012 & 0.172 & 0.005 & 0.004 & 0.066 & 0.032 \\
\hline Norm & 2.00 & 2.00 & 2.00 & 2.00 & 4.36 & 9.27 & 200.00 & 2.65 & 2.00 & 64.23 & 1.41 & 2.00 & 2.00 & 9.17 \\
\hline
\end{tabular}

Table 13b. TOPSIS decision matrix $D$ for selecting suppliers of forklift filters

\begin{tabular}{|c|c|c|c|c|c|c|c|c|c|c|c|c|c|c|c|}
\hline SF15 & SF16 & SF17 & SF18 & SF19 & SF20 & SF21 & SF22 & SF23 & SF24 & SF25 & SF26 & SF27 & SF28 & SF29 & F6 \\
\hline 300 & 1 & 1 & 53478 & 0.038 & 30 & 1 & 1 & 1 & 1 & 40 & 1 & 1 & 0 & 1 & 8.5 \\
\hline 300 & 1 & 1 & 56048 & 0.038 & 30 & 1 & 1 & 0 & 1 & 40 & 1 & 1 & 1 & 1 & 8 \\
\hline 300 & 1 & 1 & 56436 & 0.008 & 30 & 1 & 1 & 0 & 1 & 40 & 1 & 1 & 0 & 1 & 8.4 \\
\hline 300 & 1 & 1 & 55304 & 0.081 & 30 & 1 & 1 & 1 & 1 & 40 & 1 & 0 & 0 & 1 & 9 \\
\hline 300 & 2 & 1 & 53478 & 1 & 30 & 1 & 2 & 1 & 1 & 100 & 1 & 1 & 1 & 2 & 8 \\
\hline 0 & 1 & 0 & 56436 & 0 & 0 & 0 & 1 & 0 & 0 & 0 & 0 & 0 & 0 & 1 & 9 \\
\hline 0.034 & 0.026 & 0.174 & 0.021 & 0.009 & 0.053 & 0.011 & 0.002 & 0.011 & 0.002 & 0.012 & 0.014 & 0.005 & 0.002 & 0.015 & 0.040 \\
\hline 600.00 & 2.00 & 2.00 & 110656.36 & 0.10 & 60.00 & 2.00 & 2.00 & 1.41 & 2.00 & 80.00 & 2.00 & 1.73 & 1.00 & 2.00 & 16.96 \\
\hline
\end{tabular}

Table 14a. Normalized TOPSIS decision matrix $N$ for selecting suppliers of forklift filters

\begin{tabular}{|c|c|c|c|c|c|c|c|c|c|c|c|c|c|c|}
\hline & SF1 & SF2 & SF3 & SF4 & SF5 & SF6 & SF7 & SF8 & SF9 & SF10 & SF11 & SF12 & SF13 & SF14 \\
\hline S1 & 0.500 & 0.500 & 0.500 & 0.000 & 0.000 & 0.323 & 0.500 & 0.756 & 0.500 & 0.327 & 0.000 & 0.500 & 0.500 & 0.546 \\
\hline S2 & 0.500 & 0.500 & 0.500 & 0000 & 0.688 & 0.539 & 0.500 & 0.378 & 0.500 & 0.654 & 0.000 & 0.500 & 0.500 & 0.327 \\
\hline S3 & 0.500 & 0.500 & 0.500 & 0.000 & 0.688 & 0.647 & 0.500 & 0.378 & 0.500 & 0.607 & 0.707 & 0.500 & 0.500 & 0.546 \\
\hline S4 & 0.500 & 0.500 & 0.500 & 0.000 & 0.229 & 0.431 & 0.500 & 0.378 & 0.500 & 0.311 & 0.707 & 0.500 & 0.500 & 0.546 \\
\hline A+ & 0.500 & 0.500 & 0.500 & 0.000 & 0.000 & 0.323 & 0.500 & 0.756 & 0.500 & 0.654 & 0.707 & 1.000 & 0.500 & 0.546 \\
\hline A- & 0.000 & 0.000 & 0.000 & 0.000 & 0.688 & 0.647 & 0.000 & 0.378 & 0.000 & 0.311 & 0.000 & 0.500 & 0.000 & 0.327 \\
\hline W & 0.037 & 0.029 & 0.031 & 0.008 & 0.118 & 0.025 & 0.018 & 0.010 & 0.012 & 0.172 & 0.005 & 0.004 & 0.066 & 0.032 \\
\hline
\end{tabular}


Table 14b. Normalized TOPSIS decision matrix $N$ for selecting suppliers of forklift filters

\begin{tabular}{|c|c|c|c|c|c|c|c|c|c|c|c|c|c|c|c|}
\hline SF15 & SF16 & SF17 & SF18 & SF19 & SF20 & SF21 & SF22 & SF23 & SF24 & SF25 & SF26 & SF27 & SF28 & SF29 & F6 \\
\hline 0.500 & 0.500 & 0.500 & 0.483 & 0.390 & 0.500 & 4.250 & 0.500 & 0.707 & 0.500 & 0.500 & 0.500 & 0.577 & 0.000 & 0.500 & 0.501 \\
\hline 0.500 & 0.500 & 0.500 & 0.507 & 0.390 & 0.500 & 4.000 & 0.500 & 0.000 & 0.500 & 0.500 & 0.500 & 0.577 & 1.000 & 0.500 & 0472 \\
\hline 0.500 & 0.500 & 0.500 & 0.510 & 0.082 & 0.500 & 4.200 & 0.500 & 0.000 & 0.500 & 0.500 & 0.500 & 0.577 & 0.000 & 0.500 & 0.495 \\
\hline 0.500 & 0.500 & 0.500 & 0.500 & 0.830 & 0.500 & 4.500 & 0.500 & 0.707 & 0.500 & 0.500 & 0.500 & 0.000 & 0.000 & 0.500 & 0.531 \\
\hline 0.500 & 1.000 & 0.500 & 0.483 & 10.253 & 0.500 & 4.000 & 1.000 & 0.707 & 0.500 & 1.250 & 0.500 & 0.577 & 1.000 & 1.000 & 0.472 \\
\hline 0.000 & 0.500 & 0.000 & 0.510 & 0.000 & 0.000 & 4.500 & 0.500 & 0.000 & 0.000 & 0.000 & 0.000 & 0.000 & 0.000 & 0.500 & 0.531 \\
\hline 0.034 & 0.026 & 0.174 & 0.021 & 0.009 & 0.053 & 0.011 & 0.002 & 0.011 & 0.002 & 0.012 & 0.014 & 0.005 & 0.002 & 0.015 & 0.040 \\
\hline
\end{tabular}

Table 15a. Weighted and Normalized TOPSIS decision matrix V for emergency departments with respect to subcriteria

\begin{tabular}{|c|c|c|c|c|c|c|c|c|c|c|c|c|c|c|}
\hline & SF1 & SF2 & SF3 & SF4 & SF5 & SF6 & SF7 & SF8 & SF9 & SF10 & SF11 & SF12 & SF13 & SF14 \\
\hline S1 & 0.019 & 0.014 & 0.015 & 0.000 & 0.000 & 0.008 & 0.009 & 0.008 & 0.006 & 0.056 & 0.000 & 0.002 & 0.033 & 0.017 \\
\hline S2 & 0.019 & 0.014 & 0.015 & 0.000 & 0.081 & 0.014 & 0.009 & 0.004 & 0.006 & 0.112 & 0.000 & 0.002 & 0.033 & 0.010 \\
\hline S3 & 0.019 & 0.014 & 0.015 & 0.000 & 0.081 & 0.016 & 0.009 & 0.004 & 0.006 & 0.104 & 0.003 & 0.002 & 0.033 & 0.017 \\
\hline S4 & 0.019 & 0.014 & 0.015 & 0.000 & 0.027 & 0.011 & 0.009 & 0.004 & 0.006 & 0.053 & 0.003 & 0.002 & 0.033 & 0.017 \\
\hline $\mathrm{A}+$ & 0.019 & 0.014 & 0.015 & 0.000 & 0.000 & 0.008 & 0.009 & 0.008 & 0.006 & 0.112 & 0.003 & 0.004 & 0.033 & 0.017 \\
\hline A- & 0.000 & 0.000 & 0.000 & 0.000 & 0.081 & 0.016 & 0.000 & 0.004 & 0.000 & 0.053 & 0.000 & 0.002 & 0.000 & 0.010 \\
\hline
\end{tabular}

Table 15b. Weighted and Normalized TOPSIS decision matrix V for emergency departments with respect to subcriteria

\begin{tabular}{|c|c|c|c|c|c|c|c|c|c|c|c|c|c|c|c|}
\hline SF15 & SF16 & SF17 & SF18 & SF19 & SF20 & SF21 & SF22 & SF23 & SF24 & SF25 & SF26 & SF27 & SF28 & SF29 & F6 \\
\hline 0.017 & 0.013 & 0.087 & 0.010 & 0.004 & 0.026 & 0.046 & 0.001 & 0.007 & 0.001 & 0.006 & 0.007 & 0.003 & 0.000 & 0.008 & 0.020 \\
\hline 0.017 & 0.013 & 0.087 & 0.011 & 0.004 & 0.026 & 0.044 & 0.001 & 0.000 & 0.001 & 0.006 & 0.007 & 0.003 & 0.002 & 0.008 & 0.019 \\
\hline 0.017 & 0.013 & 0.087 & 0.011 & 0.001 & 0.026 & 0.046 & 0.001 & 0.000 & 0.001 & 0.006 & 0.007 & 0.003 & 0.000 & 0.008 & 0.020 \\
\hline 0.017 & 0.013 & 0.087 & 0.010 & 0.008 & 0.026 & 0.049 & 0.001 & 0.007 & 0.001 & 0.006 & 0.007 & 0.000 & 0.000 & 0.008 & 0.021 \\
\hline 0.017 & 0.026 & 0.087 & 0.010 & 0.096 & 0.026 & 0.044 & 0.002 & 0.007 & 0.001 & 0.015 & 0.007 & 0.003 & 0.002 & 0.015 & 0.019 \\
\hline 0.000 & 0.013 & 0.000 & 0.011 & 0.000 & 0.000 & 0.049 & 0.001 & 0.000 & 0.000 & 0.000 & 0.000 & 0.000 & 0.000 & 0.008 & 0.021 \\
\hline
\end{tabular}


Table 16. Separation from the positive solution

\begin{tabular}{|c|c|c|c|c|}
\hline & S1 & S2 & S3 & S4 \\
\hline SF1 & 0.0000 & 0.0000 & 0.0000 & 0.0000 \\
\hline SF2 & 0.0000 & 0.0000 & 0.0000 & 0.0000 \\
\hline SF3 & 0.0000 & 0.0000 & 0.0000 & 0.0000 \\
\hline SF4 & 0.0000 & 0.0000 & 0.0000 & 0.0000 \\
\hline SF5 & 0.0000 & 0.0661 & 0.0661 & 0.0073 \\
\hline SF6 & 0.0000 & 0.0003 & 0.0000 & 0.0001 \\
\hline SF7 & 0.0000 & 0.0000 & 0.0000 & 0.0000 \\
\hline SF8 & 0.0000 & 0.0002 & 0.0007 & 0.0002 \\
\hline SF9 & 0.0000 & 0.0000 & 0.0000 & 0.0000 \\
\hline SF10 & 0.0315 & 0.0000 & 0.0002 & 0.0346 \\
\hline SF11 & 0.0001 & 0.0001 & 0.0000 & 0.0000 \\
\hline SF12 & 0.0000 & 0.0000 & 0.0006 & 0.0000 \\
\hline SF13 & 0.0000 & 0.0000 & 0.0000 & 0.0000 \\
\hline SF14 & 0.0000 & 0.0005 & 0.0000 & 0.0000 \\
\hline SF15 & 0.0000 & 0.0000 & 0.0000 & 0.0000 \\
\hline SF16 & 0.0000 & 0.0000 & 0.0000 & 0.0000 \\
\hline SF17 & 0.0017 & 0.0017 & 0.0017 & 0.0017 \\
\hline SF18 & 0.0000 & 0.0000 & 0.0000 & 0.0000 \\
\hline SF19 & 0.0845 & 0.0845 & 0.0899 & 0.0772 \\
\hline SF20 & 0.0000 & 0.0000 & 0.0000 & 0.0000 \\
\hline SF21 & 0.0001 & 0.0000 & 0.0001 & 0.0003 \\
\hline SF22 & 0.0000 & 0.0000 & 0.0000 & 0.0000 \\
\hline SF23 & 0.0000 & 0.0006 & 0.0006 & 0.0000 \\
\hline SF24 & 0.0000 & 0.0000 & 0.0000 & 0.0000 \\
\hline SF25 & 0.0009 & 0.0009 & 0.0009 & 0.0009 \\
\hline SF26 & 0.0000 & 0.0000 & 0.0000 & 0.0000 \\
\hline SF27 & 0.0000 & 0.0000 & 0.0000 & 0.0001 \\
\hline SF28 & 0.0001 & 0.0000 & 0.0001 & 0.0001 \\
\hline SF29 & 0.0006 & 0.0006 & 0.0006 & 0.0006 \\
\hline F6 & 0.0000 & 0.0000 & 0.0000 & 0.0001 \\
\hline$S_{i}^{+}$ & 0.109288 & 0.124277 & 0.127013 & 11.0884 \\
\hline & & & & \\
\hline & & & & \\
\hline
\end{tabular}

Table 17. Separation from the negative solution

\begin{tabular}{|c|c|c|c|c|}
\hline & S1 & S2 & S3 & S4 \\
\hline SF1 & 0.0034 & 0.0034 & 0.0034 & 0.0034 \\
\hline SF2 & 0.0021 & 0.0021 & 0.0021 & 0.0021 \\
\hline SF3 & 0.0023 & 0.0023 & 0.0023 & 0.0023 \\
\hline SF4 & 0.0000 & 0.0000 & 0.0000 & 0.0000 \\
\hline SF5 & 0.0661 & 0.0000 & 0.0000 & 0.0294 \\
\hline SF6 & 0.0007 & 0.0001 & 0.0000 & 0.0003 \\
\hline SF7 & 0.0008 & 0.0008 & 0.0008 & 0.0008 \\
\hline SF8 & 0.0002 & 0.0000 & 0.0000 & 0.0000 \\
\hline SF9 & 0.0004 & 0.0004 & 0.0004 & 0.0004 \\
\hline SF10 & 0.0001 & 0.0346 & 0.0258 & 0.0000 \\
\hline SF11 & 0.0000 & 0.0000 & 0.0001 & 0.0001 \\
\hline SF12 & 0.0000 & 0.0000 & 0.0000 & 0.0000 \\
\hline SF13 & 0.0110 & 0.0110 & 0.0110 & 0.0110 \\
\hline SF14 & 0.0005 & 0.0000 & 0.0005 & 0.0005 \\
\hline SF15 & 0.0030 & 0.0030 & 0.0030 & 0.0030 \\
\hline SF16 & 0.0000 & 0.0000 & 0.0000 & 0.0000 \\
\hline SF17 & 0.0753 & 0.0753 & 0.0753 & 0.0753 \\
\hline SF18 & 0.0000 & 0.0000 & 0.0000 & 0.0000 \\
\hline SF19 & 0.0001 & 0.0001 & 0.0000 & 0.0006 \\
\hline SF20 & 0.0070 & 0.0070 & 0.0070 & 0.0070 \\
\hline SF21 & 0.0001 & 0.0003 & 0.0003 & 0.0000 \\
\hline SF22 & 0.0000 & 0.0000 & 0.0000 & 0.0000 \\
\hline SF23 & 0.0006 & 0.0000 & 0.0000 & 0.0006 \\
\hline SF24 & 0.0000 & 0.0000 & 0.0000 & 0.0000 \\
\hline & & & & \\
\hline
\end{tabular}




\begin{tabular}{|c|c|c|c|c|}
\hline SF25 & 0.0004 & 0.0004 & 0.0004 & 0.0004 \\
\hline SF26 & 0.0005 & 0.0005 & 0.0005 & 0.0005 \\
\hline SF27 & 0.0001 & 0.0001 & 0.0001 & 0.0000 \\
\hline SF28 & 0.0000 & 0.0001 & 0.0000 & 0.0000 \\
\hline SF29 & 0.0000 & 0.0000 & 0.0000 & 0.0000 \\
\hline F6 & 0.0000 & 0.0001 & 0.0000 & 0.0000 \\
\hline$S_{i}^{-}$ & 0.13211 & 0.11892 & 0.11522 & 0.11731 \\
\hline
\end{tabular}

The rank of suppliers of forklift filters and closeness coefficients $C C_{i}^{*}$ is presented in Figure 7. These values were calculated using Eq.35. Based on the results, it can be observed that all the suppliers are not good candidates for effectively providing forklift filters according to the minimum score set by the company $\left(\mathrm{CC}^{*}<0.75\right)$. In particular, S2 achieved first place with 0.609 while S3 obtained the lowest score (0.401). However, a distance between the current status and the ideal scenario (both positive and negative) can be appreciated in each potential supplier through Tables 16 and Table 17 correspondingly. The separation measures are useful to identify the strengths (sub-criteria/criteria whose distance from $A^{+}$is equal to 0 ) and weaknesses of each potential supplier (sub-criteria/criteria whose distance from $A^{+}$is higher than zero $\|$distance from $A^{-}$is equal to 0 ). We particularly focused on detecting the weaknesses of each provider to support continuous improvement and propel suppliers with highest potential for meeting a firm's needs consistently. In detail, S4 does not comply with international OHSAS 14001 regulations (SF2), which may represent significant delays for manufacturers when implementing environmental policies and targeting reduced carbon footprint. Furthermore, it can be appreciated that SF10 (Experience in the market) is equal to NIS since this company is less experienced compared to the others. On a different note, it is noted that S4 neither use eco-friendly technology (SF22; Separation from NIS $=0$ ) in the production process of its forklift filters nor consider environmental design requirements (SF24; Separation from NIS $=0$ ). This highly compromises its eligibility by mining companies targeting reduced carbon footprint. Ultimately, $\mathrm{S} 4$ does not have any evidence of the adoption of eco-friendly packaging (SF27; Separation from NIS = 0) and labelling (SF28; Separation from NIS =0), which end up hindering its access to demanding international markets. It is then of paramount importance to detect the current gaps of its environmental management system so that future sustainability can be further ensured.

On the other hand, S3 offers the longest supply lead-time - SF6 (6 days) which is not attractive for mining companies seeking for reducing the inventory levels and costs throughout the supply chain. In addition, $\mathrm{S} 3$ is the provider with the farthest location (SF18 $=56436 \mathrm{~km}$; Separation from NIS $=0$ ) which may increase its lead-time variability and subsequently augment the idle time in the manufacturing process (Ortiz et al. 2016). Similar to S4, S3 should upgrade the performance of its green management system for effectively contributing to the environmental policy of the mining industry. In this regard, it is advised to adopt sustainable packaging (i.e. biodegradable plastics and plant-based plastics), while reducing packaging needs without compromising the filter protection (SF27; Separation from NIS $=0$ ). Moreover, it is recommended using green stickers reducing the negative environmental impact caused by the current filter design which uses contaminants derived from printing processes (SF28; Separation from NIS $=0$ ). Regarding S2, the main disadvantage that has been detected is the low number of filter brands (SF14 = 3; Separation from NIS $=0$ ) managed by this supplier. In this regard, S2 should establish new branding alliances to provide a wider offer of forklift filters and subsequently support the product portfolio of the 
manufacturers. Additionally, S2, in spite of its first place in this study, should diminish the response time (SF5 = 3 days; Separation from NIS $=0$ ) for satisfactorily closing a complaint. A delayed feedback or no follow-up may cause possible sanctions, cost overruns, and unsatisfied customers. Moreover, it should foster the implementation of an E-business platform (SF11) so that supplier-customer can be better administered. Finally, S1 should work on the implementation of an R\&D department (SF16) in parallel with a CRM software (SF11) enabling the production of forklift filters with better performance, durability and competitive price; thereby, a sustainable supplier-manufacturer relation can be ensured. Moreover, its location $(\mathrm{SF} 18=53478 \mathrm{~km}$; Separation from PIS = 0.00476) may represent a disadvantage for the heavy-machinery manufacturers since the delivery performance could decrease while the logistics and inventory costs may rise. Aside from these aspects, weaknesses were also detected in environmentrelated sub-criteria. In this respect, it is recommended: i) creating a green business budget, ii) setting a green team supporting the design and implementation of green practices within the company iii) using biodegradable labeling along with recyclable raw materials, and iv) install energy efficiency systems in the technology used for the production of forklift filters.

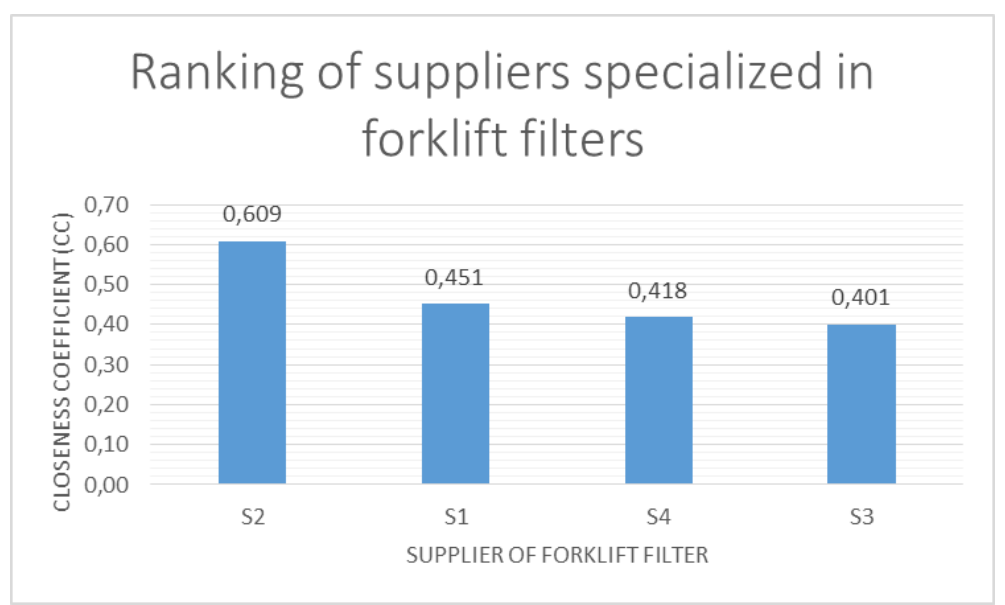

Figure 7. Closeness coefficients $\left(C C_{i}^{*}\right)$ for suppliers of forklift filters

\section{Conclusion}

Sustainability practices are a necessity for the survival of the planet. If not adopted, the live on earth is in danger of extinction. All sectors are affected and therefore the adoption of sustainable practices has become an important consideration for business organizations, especially with regard to their supply chains. These practices can help them to growth sustainably in the long term. One core practice is the supplier selection, which is key for the improvement of the supply chain performance. Thus, a structured and sustainability focused evaluation approach for supplier selection is needed among business organizations.

In this paper, we have introduced an integrated hybrid model with Fuzzy AHP, Fuzzy DEMATEL, and TOPSIS to evaluate the supplier selection decision with the recommendation of using sustainability factors. An 'hybrid model' is a procedure where the output of one technique becomes the input of a subsequent technique (Stephen,Labib 2018). This is different from 'hybrid modelling', where independent techniques are used to study the same problem in different ways. Hence the paper contributes 
to hybrid model and complements the application of other hybrid models in other applications (Kumar et al. 2019; López,Ishizaka 2019; Abastante et al. 2018; Krejčí,Ishizaka 2018; Ihrig et al. 2017; Ishizaka,Pereira 2016; Corrente et al. 2016; Ishizaka et al. 2016; Ishizaka,Nemery 2013b).

The hybrid model can be extended to all industries irrespective of their nature and location. These models can be applied to supplier evaluation and selection systems along with other selection problems. For companies to attain overall sustainability, incorporating these sustainable suppliers in their supply chains will change the way business is done, which can lead to long time sustainability. However, all the suppliers should be periodically evaluated and measured on sustainable criteria and rated on a performance rating scale. In a future work, we aim to develop this performance evaluation system that could be used to identify and expose poor sustainable performers in the supply chain and help the companies develop better sustainable suppliers.

\section{References}

Abastante, F., Corrente, S., Greco, S., Ishizaka, A., Lami, I.: Choice architecture for architecture choices: Evaluating social housing initiatives putting together a parsimonious AHP methodology and the Choquet integral. Land Use Policy 78, 748-762 (2018). doi:https://doi.org/10.1016/j.landusepol.2018.07.037

Abdulgader, F., Eid, R., Daneshvar Rouyendegh, B.: Development of Decision Support Model for Selecting a Maintenance Plan Using a Fuzzy MCDM Approach: A Theoretical Framework. Applied Computational Intelligence and Soft Computing 2018, 14 (2018). doi:10.1155/2018/9346945

Amid, A., Ghodsypour, S., O’Brien, C.: A weighted max-min model for fuzzy multi-objective supplier selection in a supply chain. International Journal of Production Economics 131(1), 139-145 (2011). doi:https://doi.org/10.1016/j.ijpe.2010.04.044

Ashtiani, B., Haghighirad, F., Makui, A., Montazer, G.: Extension of fuzzy TOPSIS method based on interval-valued fuzzy sets. Applied Soft Computing 9(2), 457-461 (2009). doi:https://doi.org/10.1016/j.asoc.2008.05.005

Bai, C., Sarkis, J.: Integrating sustainability into supplier selection with grey system and rough set methodologies. International Journal of Production Economics 124(1), 252-264 (2010). doi:https://doi.org/10.1016/j.ijpe.2009.11.023

Barrios, M., De Felice, F., Negrete, K., Romero, B., Arenas, A., Petrillo, A.: An AHP-Topsis integrated model for selecting the most appropriate tomography equipment. International Journal of Information Technology \& Decision Making 15(04), 861-885 (2016). doi:10.1142/s021962201640006x

Barthélemy, J.: The hidden costs of IT outsourcing. MIT Sloan Management Review 42(3), 60-69 (2001)

Baykasoğlu, A., Kaplanoğlu, V., Durmuşoğlu, Z., Şahin, C.: Integrating fuzzy DEMATEL and fuzzy hierarchical TOPSIS methods for truck selection. Expert Systems with Applications 40(3), 899907 (2013). doi:https://doi.org/10.1016/j.eswa.2012.05.046

Blind, K., Mangelsdorf, A., Pohlisch, J.: The effects of cooperation in accreditation on international trade: Empirical evidence on ISO 9000 certifications. International Journal of Production Economics 198, 50-59 (2018). doi:https://doi.org/10.1016/j.ijpe.2018.01.033

Büyüközkan, G., Çifçi, G.: A novel hybrid MCDM approach based on fuzzy DEMATEL, fuzzy ANP and fuzzy TOPSIS to evaluate green suppliers. Expert Systems with Applications 39(3), 30003011 (2012). doi:https://doi.org/10.1016/j.eswa.2011.08.162 
Castka, P.: Modelling firms' interventions in ISO 9001 certification: A configurational approach. International Journal of Production Economics 201, 163-172 (2018). doi:https://doi.org/10.1016/j.ijpe.2018.05.005

Cebeci, U.: Fuzzy AHP-based decision support system for selecting ERP systems in textile industry by using balanced scorecard. Expert Systems with Applications 36(5), 8900-8909 (2009)

Chai, J., Liu, J., Ngai, E.: Application of decision-making techniques in supplier selection: A systematic review of literature. Expert Systems with Applications 40(10), 3872-3885 (2013). doi:http://dx.doi.org/10.1016/j.eswa.2012.12.040

Chan, F., Kumar, N.: Global supplier development considering risk factors using fuzzy extended AHPbased approach. Omega 35(4), 417-431 (2007). doi:https://doi.org/10.1016/j.omega.2005.08.004

Chang, B., Chang, C., Wu, C.: Fuzzy DEMATEL method for developing supplier selection criteria. Expert Systems with Applications 38(3), 1850-1858 (2011). doi:https://doi.org/10.1016/j.eswa.2010.07.114

Chen, Z., Ming, X., Zhou, T., Chang, Y.: Sustainable supplier selection for smart supply chain considering internal and external uncertainty: An integrated rough-fuzzy approach. Applied Soft Computing 87, 106004 (2020). doi:https://doi.org/10.1016/j.asoc.2019.106004

Corrente, S., Greco, S., Ishizaka, A.: Combining analytical hierarchy process and Choquet integral within non-additive robust ordinal regression. Omega(61), 2-18 (2016). doi:http://dx.doi.org/10.1016/j.omega.2015.07.003

Faisal, M., Al-Esmael, B., Sharif, K.: Supplier selection for a sustainable supply chain: Triple bottom line (3BL) and analytic network process approach. Benchmarking: An International Journal 24(7), 1956-1976 (2017). doi:10.1108/BIJ-03-2016-0042

Foss, N., Jensen, H.: Managerial meta-knowledge and adaptation: Governance choice when firms don't know their capabilities. Strategic Organization 17(2), 153-176 (2019). doi:10.1177/1476127018778717

Fryxell, G., Szeto, A.: The influence of motivations for seeking ISO 14001 certification: an empirical study of ISO 14001 certified facilities in Hong Kong. Journal of Environmental Management 65(3), 223-238 (2002). doi:https://doi.org/10.1006/jema.2001.0538

Govindan, K., Rajendran, S., Sarkis, J., Murugesan, P.: Multi criteria decision making approaches for green supplier evaluation and selection: a literature review. Journal of Cleaner Production 98, 66-83 (2015). doi:https://doi.org/10.1016/j.jclepro.2013.06.046

Guarnieri, P., Trojan, F.: Decision making on supplier selection based on social, ethical, and environmental criteria: A study in the textile industry. Resources, Conservation and Recycling 141, 347-361 (2019). doi:https://doi.org/10.1016/j.resconrec.2018.10.023

Gunasekaran, A., Lai, K., Edwin Cheng, T.: Responsive supply chain: A competitive strategy in a networked economy. Omega 36(4), 549-564 (2008). doi:https://doi.org/10.1016/j.omega.2006.12.002

Ho, W., Xu, X., Dey, P.: Multi-criteria decision making approaches for supplier evaluation and selection: A literature review. European Journal of Operational Research 202(1), 16-24 (2010). doi:DOI: 10.1016/j.ejor.2009.05.009

Igarashi, M., de Boer, L., Fet, A.: What is required for greener supplier selection? A literature review and conceptual model development. Journal of Purchasing and Supply Management 19(4), 247263 (2013). doi:https://doi.org/10.1016/j.pursup.2013.06.001

Ihrig, S., Ishizaka, A., Mohnen, A.: Target setting for indirect processes: a new hybrid method for the continuous improvement management of indirect processes. Production Planning \& Control 28(3), 220-231 (2017). doi:10.1080/09537287.2016.1254830 
Ishizaka, A.: Comparison of fuzzy logic, AHP, FAHP and hybrid fuzzy AHP for new supplier selection and its performance analysis. International Journal of Integrated Supply Management 9(1), 1-22 (2014). doi:10.1504/IJISM.2014.064353

Ishizaka, A., Nemery, P.: Multi-Criteria Decision Analysis. John Wiley \& Sons Inc, Chichester (United Kingdom) (2013a)

Ishizaka, A., Nemery, P.: A Multi-Criteria Group Decision Framework for Partner Grouping when sharing Facilities. Group Decision and Negotiation 22(4), 773-799 (2013b)

Ishizaka, A., Pereira, V.: A fair and transparent employee performance management system based on multi-criteria decision analysis and visual techniques. International Journal of Manpower 37(4), 628-659 (2016)

Ishizaka, A., Siraj, S., Nemery, P.: Which energy mix for the UK? An evolutive descriptive mapping with the integrated GAIA-AHP visualisation tool. Energy 95, 602-611 (2016)

Jindal, A., Sangwan, K.: Multi-objective fuzzy mathematical modelling of closed-loop supply chain considering economical and environmental factors. Annals of Operations Research 257(1), 95120 (2017). doi:10.1007/s10479-016-2219-z

Kahraman, C., Cebeci, U., Ulukan, Z.: Multi-criteria supplier selection using fuzzy AHP. Logistics Information Management 16(6), 382-394 (2003)

Kannan, D., Khodaverdi, R., Olfat, L., Jafarian, A., Diabat, A.: Integrated fuzzy multi criteria decision making method and multi-objective programming approach for supplier selection and order allocation in a green supply chain. Journal of Cleaner Production 47, 355-367 (2013). doi:https://doi.org/10.1016/j.jclepro.2013.02.010

Kar, A.: A hybrid group decision support system for supplier selection using analytic hierarchy process, fuzzy set theory and neural network. Journal of Computational Science 6, 23-33 (2015). doi:https://doi.org/10.1016/j.jocs.2014.11.002

Keskin, G.: Using integrated fuzzy DEMATEL and fuzzy C: means algorithm for supplier evaluation and selection. International Journal of Production Research 53(12), 3586-3602 (2015). doi:10.1080/00207543.2014.980461

Khan, S., Kusi-Sarpong, S., Arhin, F., Kusi-Sarpong, H.: Supplier sustainability performance evaluation and selection: A framework and methodology. Journal of Cleaner Production 205, 964-979 (2018). doi:https://doi.org/10.1016/j.jclepro.2018.09.144

Krejčí, J., Ishizaka, A.: FAHPSort: a fuzzy extension of the AHPSort method. International Journal of Information Technology \& Decision Making 17(04), 1119-1145 (2018). doi:10.1142/s0219622018400011

Kumar, A., Mangla, Luthra, S., Ishizaka, A.: Evaluating the human resource related soft dimensions in green supply chain management implementation. Production Planning and Control, advance online publication, doi: 10.1080/09537287.09532018.01555342 (2019)

Kusi-Sarpong, S., Sarkis, J., Wang, X.: Assessing green supply chain practices in the Ghanaian mining industry: A framework and evaluation. International Journal of Production Economics 181, 325-341 (2016). doi:https://doi.org/10.1016/j.ijpe.2016.04.002

Lau, A., Tang, E., Yam, R.: Effects of Supplier and Customer Integration on Product Innovation and Performance: Empirical Evidence in Hong Kong Manufacturers. Journal of Product Innovation Management 27(5), 761-777 (2010). doi:10.1111/j.1540-5885.2010.00749.x

Lin, K.-P., Tseng, M.-L., Pai, P.-F.: Sustainable supply chain management using approximate fuzzy DEMATEL method. Resources, Conservation and Recycling 128, 134-142 (2018). doi:https://doi.org/10.1016/j.resconrec.2016.11.017 
Lopes de Sousa Jabbour, A., Jabbour, C., Godinho Filho, M., Roubaud, D.: Industry 4.0 and the circular economy: a proposed research agenda and original roadmap for sustainable operations. Annals of Operations Research 270(1), 273-286 (2018). doi:10.1007/s10479-018-2772-8

López, C., Ishizaka, A.: A hybrid FCM-AHP approach to predict impacts of offshore outsourcing location decisions on supply chain resilience. Journal of Business Research, advance online publications, https://doi.org/10.1016/j.jbusres.2017.1009.1050 (2019).

doi:https://doi.org/10.1016/j.jbusres.2017.09.050

Luthra, S., Govindan, K., Kannan, D., Mangla, S., Garg, C.: An integrated framework for sustainable supplier selection and evaluation in supply chains. Journal of Cleaner Production 140, 16861698 (2017). doi:https://doi.org/10.1016/j.jclepro.2016.09.078

Maditati, D., Munim, Z., Schramm, H.-J., Kummer, S.: A review of green supply chain management: From bibliometric analysis to a conceptual framework and future research directions.

Resources, Conservation and Recycling 139, 150-162 (2018). doi:https://doi.org/10.1016/j.resconrec.2018.08.004

Mardani, A., Jusoh, A., Zavadskas, E.: Fuzzy multiple criteria decision-making techniques and applications - Two decades review from 1994 to 2014. Expert Systems with Applications 42(8), 4126-4148 (2015). doi:https://doi.org/10.1016/j.eswa.2015.01.003

Mehregan, M., Hashemi, S., Karimi, A., Merikhi, B.: Analysis of interactions among sustainability supplier selection criteria using ISM and fuzzy DEMATEL. International Journal of Applied Decision Sciences 7(3), 270-294 (2014)

Muduli, K., Govindan, K., Barve, A., Geng, Y.: Barriers to green supply chain management in Indian mining industries: a graph theoretic approach. Journal of Cleaner Production 47, 335-344 (2013). doi:https://doi.org/10.1016/j.jclepro.2012.10.030

Oliveira, T., Martins, M.: Understanding e-business adoption across industries in European countries. Industrial Management \& Data Systems 110(9), 1337-1354 (2010). doi:10.1108/02635571011087428

Olson, D.: Comparison of weights in TOPSIS models. Mathematical and Computer Modelling 40(7), 721-727 (2004). doi:https://doi.org/10.1016/j.mcm.2004.10.003

Orji, I., Wei, S.: A decision support tool for sustainable supplier selection in manufacturing firms. 2014 7(5), 23 (2014). doi:10.3926/jiem.1203

Ortiz-Barrios, M., Kucukaltan, B., Carvajal-Tinoco, D., Neira-Rodado, D., Jiménez, G.: Strategic hybrid approach for selecting suppliers of high-density polyethylene. Journal of Multi-Criteria Decision Analysis 24(5-6), 296-316 (2017). doi:10.1002/mcda.1617

Ortiz, M., Neira, D., Jiménez, G., Hernández, H.: Solving Flexible Job-Shop Scheduling Problem with Transfer Batches, Setup Times and Multiple Resources in Apparel Industry. In, Cham 2016. Advances in Swarm Intelligence, pp. 47-58. Springer International Publishing

Petrudi, S., Abdi, M., Goh, M.: An integrated approach to evaluate suppliers in a sustainable supply chain. Uncertain Supply Chain Management 6(4), 423-444 (2018)

Phochanikorn, P., Tan, C.: A New Extension to a Multi-Criteria Decision-Making Model for Sustainable Supplier Selection under an Intuitionistic Fuzzy Environment. Sustainability 11(19), 5413 (2019)

Prakash, C., Barua, M.: An analysis of integrated robust hybrid model for third-party reverse logistics partner selection under fuzzy environment. Resources, Conservation and Recycling 108, 63-81 (2016). doi:https://doi.org/10.1016/j.resconrec.2015.12.011

Roy, B.: The optimisation problem formulation: criticism and overstepping. Journal of the Operational Research Society 32(6), 427-436 (1981) 
Saaty, T.: A scaling method for priorities in hierarchical structures. Journal of Mathematical Psychology 15(3), 234-281 (1977)

Sauer, P., Seuring, S.: Sustainable supply chain management for minerals. Journal of Cleaner Production 151, 235-249 (2017). doi:https://doi.org/10.1016/j.jclepro.2017.03.049

Schneider, L., Wallenburg, C.: Implementing sustainable sourcing-Does purchasing need to change? Journal of Purchasing and Supply Management 18(4), 243-257 (2012). doi:https://doi.org/10.1016/j.pursup.2012.03.002

Shaw, K., Shankar, R., Yadav, S., Thakur, L.: Supplier selection using fuzzy AHP and fuzzy multiobjective linear programming for developing low carbon supply chain. Expert Systems with Applications 39(9), 8182-8192 (2012). doi:https://doi.org/10.1016/j.eswa.2012.01.149

Shen, L., Olfat, L., Govindan, K., Khodaverdi, R., Diabat, A.: A fuzzy multi criteria approach for evaluating green supplier's performance in green supply chain with linguistic preferences. Resources, Conservation and Recycling 74(0), 170-179 (2013). doi:http://dx.doi.org/10.1016/j.resconrec.2012.09.006

Si, S., You, X., Liu, H., Zhang, P.: DEMATEL Technique: A Systematic Review of the State-of-theArt Literature on Methodologies and Applications. Mathematical Problems in Engineering 2018, 3696457 (2018)

Sivrikaya, B., Kaya, A., Dursun, M., Çebi, F.: Fuzzy AHP-goal programming approach for a supplier selection problem. Research in Logistics \& Production 5(3), 271-285 (2015)

Soleimani, H., Seyyed-Esfahani, M., Shirazi, M.: A new multi-criteria scenario-based solution approach for stochastic forward/reverse supply chain network design. Annals of Operations Research 242(2), 399-421 (2016). doi:10.1007/s10479-013-1435-z

Stephen, C., Labib, A.: A hybrid model for learning from failures. Expert Systems with Applications 93, 212-222 (2018). doi:https://doi.org/10.1016/j.eswa.2017.10.031

Stringfellow, A., Teagarden, M., Nie, W.: Invisible costs in offshoring services work. Journal of Operations Management 26(2), 164-179 (2008). doi:https://doi.org/10.1016/j.jom.2007.02.009

Sultana, I., Ahmed, I., Azeem, A.: An integrated approach for multiple criteria supplier selection combining Fuzzy Delphi, Fuzzy AHP \& Fuzzy TOPSIS. Journal of Intelligent \& Fuzzy Systems 29(4), 1273-1287 (2015)

Tseng, M.-L., Islam, M., Karia, N., Fauzi, A., Afrin, S.: A literature review on green supply chain management: Trends and future challenges. Resources, Conservation and Recycling 141, 145162 (2019). doi:https://doi.org/10.1016/j.resconrec.2018.10.009

Uygun, Ö., Kaçamak, H., Kahraman, Ü.: An integrated DEMATEL and Fuzzy ANP techniques for evaluation and selection of outsourcing provider for a telecommunication company. Computers \& Industrial Engineering 86, 137-146 (2015). doi:https://doi.org/10.1016/j.cie.2014.09.014

van der Aalst, W., Dumas, M., Ouyang, C., Rozinat, A., Verbeek, E.: Conformance checking of service behavior. ACM Trans. Internet Technol. 8(3), 1-30 (2008). doi:10.1145/1361186.1361189

Vinodh, S., Anesh Ramiya, R., Gautham, S.: Application of fuzzy analytic network process for supplier selection in a manufacturing organisation. Expert Systems with Applications 38(1), 272-280 (2011). doi:https://doi.org/10.1016/j.eswa.2010.06.057

Wagner, S.: Getting innovation from suppliers. Research-Technology Management 52(1), 8-9 (2009). doi:10.1080/08956308.2009.11657543

Wang, J.-W., Cheng, C.-H., Huang, K.-C.: Fuzzy hierarchical TOPSIS for supplier selection. Applied Soft Computing 9(1), 377-386 (2009). doi:https://doi.org/10.1016/j.asoc.2008.04.014

Zavadskas, E., Govindan, K., Antucheviciene, J., Turskis, Z.: Hybrid multiple criteria decision-making methods: a review of applications for sustainability issues. Economic Research-Ekonomska Istraživanja 29(1), 857-887 (2016). doi:10.1080/1331677X.2016.1237302 
Zimmer, K., Fröhling, M., Schultmann, F.: Sustainable supplier management - a review of models supporting sustainable supplier selection, monitoring and development. International Journal of Production Research 54(5), 1412-1442 (2016). doi:10.1080/00207543.2015.1079340 